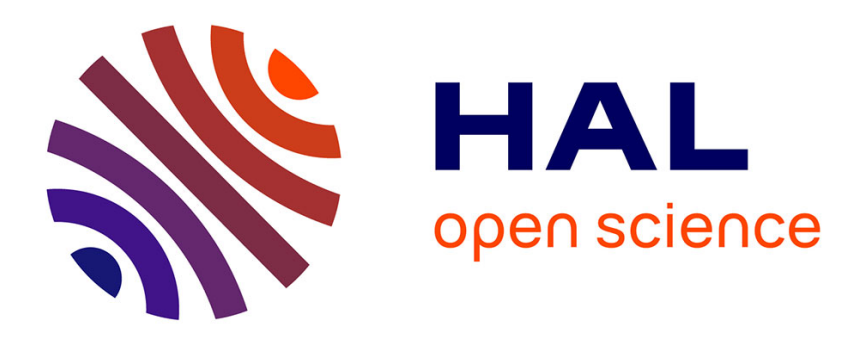

\title{
Medical Computer Vision, Virtual Reality and Robotics
}

Nicholas Ayache

\section{To cite this version:}

Nicholas Ayache. Medical Computer Vision, Virtual Reality and Robotics. Image and Vision Computing, 1995, 13 (4), pp.295-313. 10.1016/0262-8856(95)99717-F . inria-00615055

\section{HAL Id: inria-00615055 \\ https://hal.inria.fr/inria-00615055}

Submitted on 17 Aug 2011

HAL is a multi-disciplinary open access archive for the deposit and dissemination of scientific research documents, whether they are published or not. The documents may come from teaching and research institutions in France or abroad, or from public or private research centers.
L'archive ouverte pluridisciplinaire HAL, est destinée au dépôt et à la diffusion de documents scientifiques de niveau recherche, publiés ou non, émanant des établissements d'enseignement et de recherche français ou étrangers, des laboratoires publics ou privés. 


\title{
Medical computer vision, virtual reality and robotics
}

\author{
Nicholas Ayache
}

The automated analysis of 3D medical images can improve both diagnosis and therapy significantly. This automation raises a number of new fascinating research problems in the fields of computer vision, graphics and robotics. In this paper, I propose a list of such problems after a review of the current major 3D imaging modalities, and a description of the related medical needs. I then present some of the past and current work done in our research group EPIDAURE* at INRIA, on the following topics: segmentation of $3 \mathrm{D}$ images; $3 \mathrm{D}$ shape modelling; 3D rigid and nonrigid registration; 3D motion analysis; and 3D simulation of therapy. Most topics are discussed in a synthetic manner, and illustrated by results. Rigid matching is treated more thoroughly as an illustration of a transfer from computer vision towards 3D image processing. The later topics are illustrated by preliminary results, and a number of promising research tracks are suggested.

Keywords: volume image processing, medical images, 3D vision, virtual reality, medical robotics, research trends

\section{INTRODUCTION}

\section{New images}

Three-dimensional (3D) images are becoming very popular in the medical field ${ }^{1-9}$. A modern hospital each year commonly produces tens of thousands of volumetric images. They come from different modalities like magnetic resonance imagery (MRI), computed tomography imagery (CTI, also called scanner imagery), nuclear medicine imagery (NMI) or ultrasound imagery (USI).

These images share the particularity of describing the physical or chimical properties at each point of a

*EPIDAURE is a very nice location in Greece which used to be the sanctuary of ancient medicine. Today, for computer scientists, it is also a recursive acronym (in Frcnch): Epidaure, Project Image, Diagnostic AUtomatique, et RobotiquE.

INRIA - EPIDAURE Project, BP 93-06902 Sophia-Antipolis, France Paper received: 8 March 1994; revised paper received: 7 February 1995 studied volume. This information is stored in a discrete 3D matrix $I(i, j, k)$ of voxels (volume elements), called a $3 \mathrm{D}$ image because of the analogy with digital 2D images $I(i, j)$ stored as 2D matrices of pixels (picture elements). Actually, the most simple exploitation of 3D images consists in a direct visualization of the successive $2 \mathrm{D}$ images (also called cross-sections) obtained by setting one of the three coordinates $(i, j, k)$ to a constant. In fact, applying advanced 3D image processing and graphics allows much more vivid and realistic displays, as shown in Figure 1, built from a 3D MRI; Figure 2 shows a few cross-sections.

Cross-sections from the four main imaging modalitics are shown in Figure 3. In MRI, the intensity $I$ measures locally the density and structures of protons, while in

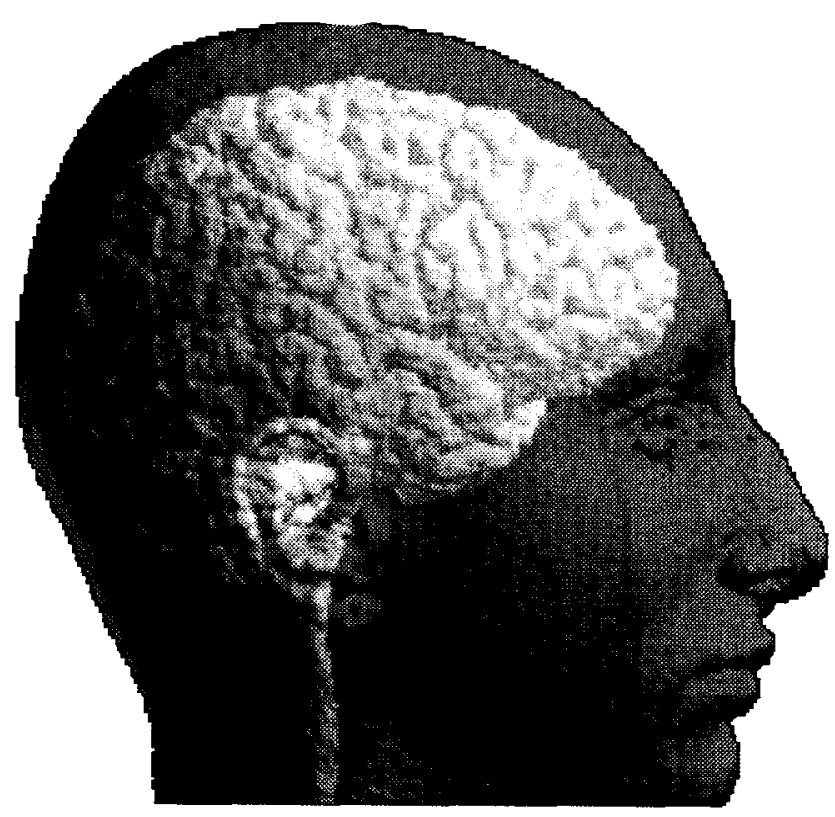

Figure $13 \mathrm{D}$ display of two well-known anatomical structures extracted automatically from a single $3 \mathrm{D}$ magnetic resonance image of the head. The automatic extraction and display of these structures involves advanced $3 \mathrm{D}$ image processing 

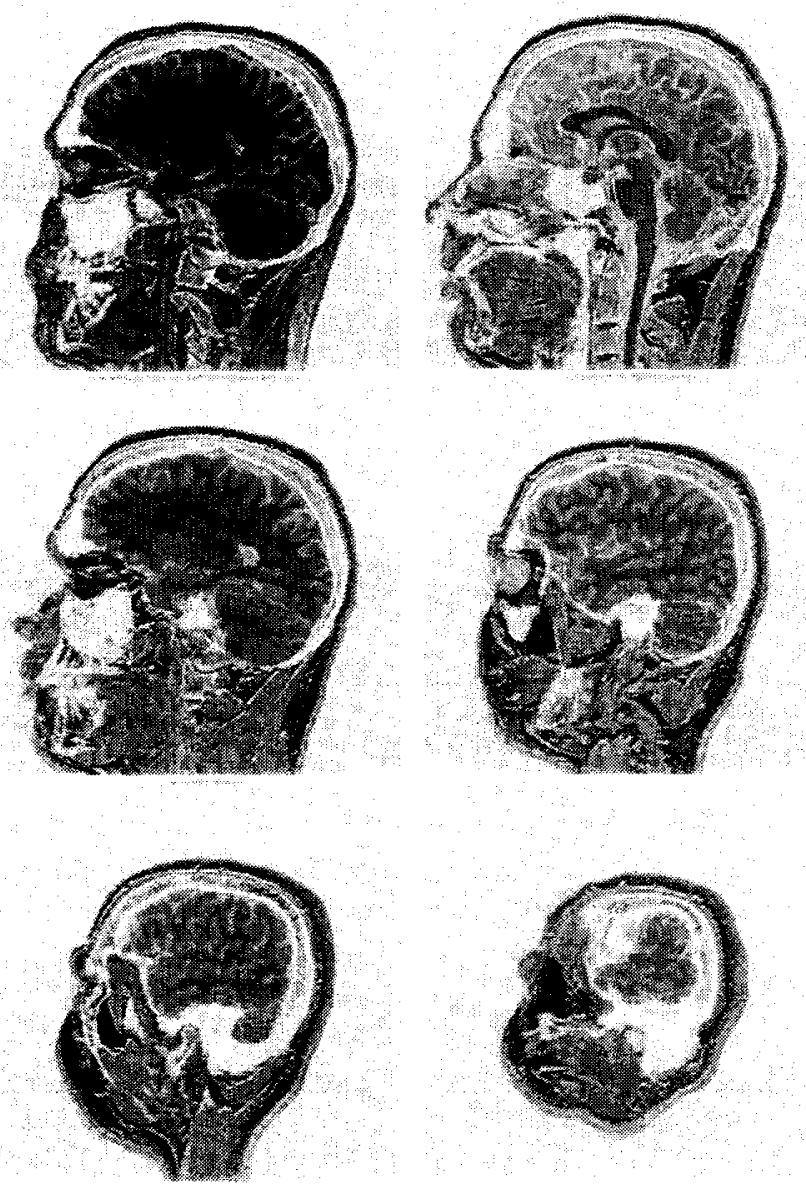

Figure 2 Cross-sections extracted from a 3D MRI image of the head

CTI, intensity measures locally the density of x-ray absorbtion. CTI and MRI provide complementary anatomical information. CTI gives very contrasted images of the bones, while MRI gives excellent descriptions of most organs and soft tissues, as well as a reasonably good description of the bones.

NMI measures locally the density of some injected radioactive molecules. It therefore provides functional information on the metabolism of the regions studied (e.g. the density of glucose used per unit of time and volume in the brain). The main sources of NMI are single photon emission computed tomography (SPECT), with positron emission tomography (PET) still being a research tool.

Finally, USI measures locally the variation of the acoustic impedance (a function of the speed of ultrasound propagation). Although most commonly used in two dimensions, ultrasound images can also be acquired in $3 \mathrm{D}^{10,11}$. Ultrasound images are easily acquired at a very fast rate, giving both anatomical information (boundaries of anatomical structures usually correspond to variations of the acoustic impedance), and dynamic information (e.g. the heart motion). Dynamic information can also be obtained by gated (i.e. synchronized) MRI or NMI.

Although USI and MRI are recognized as noninvasive (non-dangerous) techniques, this is not the
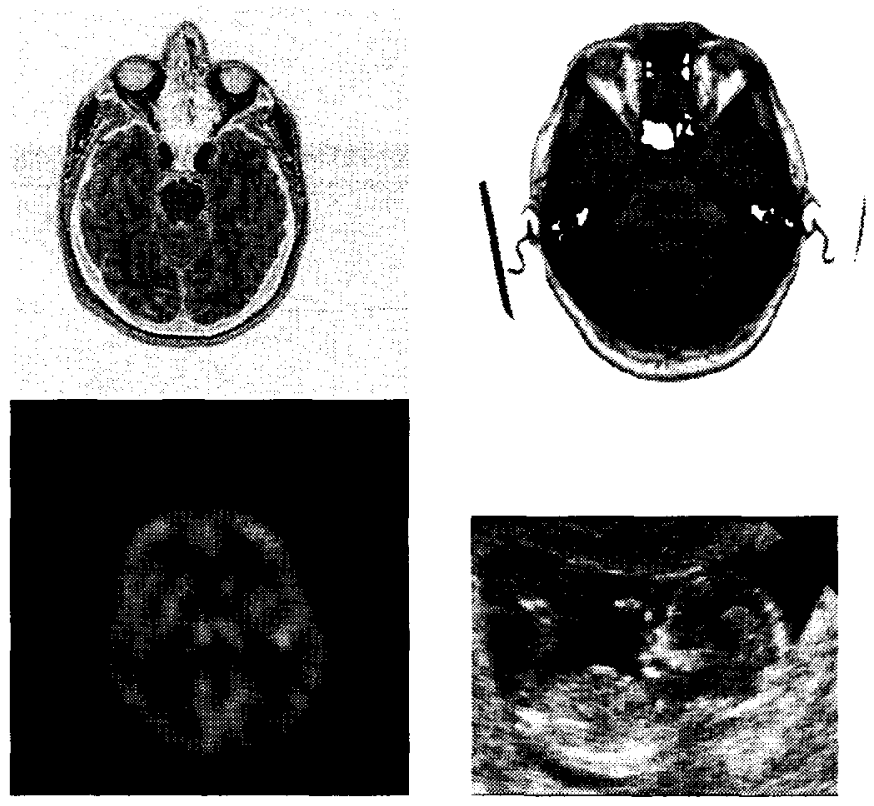

Figure 3 Four different modalities of acquisition of 3D images: MRI, CTI, NMI and USI. Although each image is produced in three dimensions, only one cross-section is shown here. The first three images show the head; the last is a young foetus $(7 \mathrm{~cm}$ !)

case for CTI and NMI, which involve radioactive materials. The cost of equipment varies a lot from one modality to another: currently the cheapest is USI (typically, less than $100 \mathrm{k \$}$ ), while the most expensive is MRI (typically several M\$).

Ncw 3D imagery devices are cmerging, like angiographic MRI, which describes the anatomy of the vascular system, magneto-encephalography equipment, which measures magnetic field variations, or functional MRI, which provides metabolism information (like NMI), but with a non-invasive method. These new modalities are still at the research stage, but may lead to major 3D imaging devices in the near future.

\section{New markets}

The market of the production of medical images was evaluated at being 8 billion (US dollars) in 1991 12,13 , and shows approximately an increase of $10 \%$ per year. Among these figures, MRI represents currently a market of 1 billion, with a strong increase of approximately $20 \%$ per year ${ }^{14}$.

Besides the production itself, $3 \mathrm{D}$ image processing is the most recent market. Almost non-existent a few years ago, it was evaluated at $\$ 350$ million in 1992 , with a planned evolution between $20-40 \%$ per year during the next five years.

This comes from the new capabilities demonstrated by computer vision applied to 3D imagery. Not only does it provide better diagnosis tools, but also new possibilitics for therapy. This is truc in particular for brain and skull surgery, laparoscopy and radiotherapy, where simulation tools can be tested in advance, 
sometimes with the help of virtual reality, and used during the intervention as guiding tools ${ }^{11,15,16}$. In some cases, even robots can use pre-operative and peroperative 3D imagery to complete precisely some specific medical gestures prepared during a simulation phase $^{17-20}$.

One must notice that $3 \mathrm{D}$ imagery is also in expansion in fields other than medical. In biology, confocal microscopy produces voxel images at a microscopic scale. In industry, non-destructive inspection of important parts, like turbine blades, for instance, is sometimes made with CTI. Finally, in geology, large petroleum companies like Elf-Aquitaine, for instance, have bought scanners (CTI) to analyse core samples.

\section{New medical needs}

Exploiting 3D images in their new format (a 3D matrix of numbers) is usually a very awkward task. For instance, it is now quite easy to acquire MRI images of the head with a resolution of about a millimeter in each of the three directions. Such an image can have $256^{3}$ voxels, which represents about 17 Mbyte of data. High resolution $3 \mathrm{D}$ images of the heart can also be acquired during a time sequence, which represent spatiotemporal data in four dimensions. In both cases, displaying $2 \mathrm{D}$ cross-sections one at a time is no longer sufficient to establish a reliable diagnosis or prepare a critical therapy.

Moreover, the complexity of the anatomical structures can make their identification difficult, and the use of multimodal complementary images requires accurate spatial registration. Long-term study of a patient's evolution also requires accurate spatio-temporal registration.

We identified the automation of the following tasks as being crucial needs for improvment in diagnosis and therapy:

1. Interactive visualization must really be $3 \mathrm{D}$, with dynamic animation capabilities. The result could be seen as a flight simulation within the anatomical structures of the human body. A recent review of the state-of-the-art can be found in Stytz et al. $^{21}$.

2. Quantification of shapes, textures and motion must provide the physician with a reduced set of parameters useful to establish his diagnosis, study temporal evolution, and make inter-patient comparisons. This must be true for the analysis of static and dynamic images.

3. Registration of 3D images must be possible for a given patient between single- or multi-modality $3 \mathrm{D}$ images. This spatial superposition is a necessary condition to study the evolution of a pathology in great depth, or to take full advantage of the complementarity information available in multimodality imagery. Extensions to the multi-patient cases are also useful, because it allows subtle interpatient comparisons.

4. Identification of anatomical structures within $3 \mathrm{D}$ images requires the construction of computerized anatomical atlases, and the design of matching procedures between atlases and 3D images. Such a registration would provide substantial help for a faster interpretation of the most complex regions of the body (e.g. the brain), and it is a prerequisite to solve the previous multi-patient registration problem and to help planning (see below).

5. Planning, Simulation and Control of therapy, especially for delicate and complex surgery (e.g. brain and cranio-facial surgery, hip, spine and eye surgery, laparoscopy, etc.), and also for radiotherapy: this is an ultimate goal. The therapist, with the help of interactive visualization tools applied to quantified, registered and identified $3 \mathrm{D}$ images, could planify in advance its intervention, taking advantage of all the planning advice available, and then observe and compare predicted results before any operation is done. Once the best solution is chosen, the actual intervention could then be controlled by passive or active mechanical devices, with the help of peroperative images and other sensors, like force sensors.

\section{New image properties}

To fulfil these medical needs, it is necessary to address a number of challenging new computer vision and robotics problems ${ }^{22,23}$. Most of these problems are quite new, not only because images are in three dimensions, but also because usual approximations like polyhedral models or typical assumptions like rigidity rarely apply to medical objects. This opens a large range of new problems sometimes more complex than their counterparts in 2D image analysis.

On the other hand, specific properties of $3 \mathrm{D}$ medical imagery can be exploited very fruitfully. For instance, contrary to video images of a 3D scene, geometric measurements are not projective but Euclidean measurements. Three-dimensional coordinates of structures are readily available!

Moreover, one can usually exploit the intrinsic value of intensity, which is generally related in a simple way to the physical or physiological properties of the considered region; this is almost never the case with video images, where intensity varies with illumination, point of view, surface orientation, etc.)

Also, a priori knowledge is high, in the sense that physicians usually have protocols (unfortunately, depending on the image modality) to acquire images of a given part of the body, and different patients tend to have similar structures at similar locations!

Finally, having a dense set of $3 D$ data provides a better local regularization when computing local differential properties, as we shall see later. 


\section{New computer vision, graphics and robotics issues}

Having listed the medical needs and the new image properties, I now set a list of computer vision, graphics and robotics issues which I believe are central problems:

1. $3 D$ segmentation of images: the goal is to partition the raw 3D image into regions corresponding to meaningful anatomic structures. It is a prerequisite to most of the medical needs listed above. Efficient segmentation requires the modelling and extraction of $3 \mathrm{D}$ static or dynamic edges and of 3D texture, as well as the generalization of $2 \mathrm{D}$ digital topology and mathematical morphology in $3 \mathrm{D}$.

2. $3 D$ shape modelling: this is mainly a prerequisite to solve registration and identification needs, but also for efficient visualization. It is necessary to describe non-polyhedral 3D shapes with a reduced number of intrinsic features. This involves mainly computational and differential geometry.

3. $3 D$ matching of $3 \mathrm{D}$ shapes: once segmented and modelled, new algorithms must be designed to reliably and accurately match such representations together, both in rigid and nonrigid cases. This is necessary to solve registration and identification needs.

4. $3 D$ motion analysis: this requires the development of new tools to process sequences of $3 \mathrm{D}$ images (i.e. 4D images!), in order to track and describe rigid and nonrigid motion of $3 \mathrm{D}$ anatomical structures. This is necessary for the quantification of motion needs.

5. Dynamic physical modes of anatomical structures should be developed to provide realistic simulation of interaction with $3 \mathrm{D}$ images. This is required for the planning and simulation of therapy. Physical models can also help solving the previous 3D motion analysis problems.

6. Geometric reasoning is required to help therapeutic planning, in particular to determine trajectories of beam sources in radiotherapy, and the succession of accurate medical gestures in surgery.

7. Virtual reality environments should be developed to provide realistic interactive visualization and to help planning and simulation.

8. Dedicated medical robots, possibly passive or semiactive, equipped with specific sensors (force sensing, optical or ultrasound positioning, etc.) must be developed for the automatic control of therapy.

As one should notice, these problems are mainly computer vision and robotics problems, also involving graphics. In the following, I address them (except the last one, but see ${ }^{18,19,24}$ for spectacular examples of dedicated medical robots) by presenting the research conducted during the past five years in the research group EPIDAURE at INRIA. I present the basic lines of this research, the main results, and indicate some promising research tracks. References arc madc primarily to the papers published by the EPIDAURE group, although I have tried to add a significant (but necessarily incomplete!) list of complementary references. I apologize in advance for all the missing ones.

\section{SEGMENTATION OF 3D IMAGES}

Segmentation of 3D images has similarities with the classical problem of segmenting $2 \mathrm{D}$ images. The purpose is the same, namely to partition the original set of image points into subsets corresponding to meaningful objects. As for $2 \mathrm{D}$ image processing, both region- and contour-based approaches apply, with the specificity that regions are now volumes and that edges become surfaces.

We have found that a set of generic tools was quite effective in solving completely a number of specific segmentation problems, both in static and dynamic images. These include 3D edge extraction, 3D digital topology and mathematical morphology operators, 2D and $3 \mathrm{D}$ active contours, and $3 \mathrm{D}$ texture analysis tools. We found that, combined together, these tools could solve the problem of segmenting major anatomical structures in CTI and MRI, and also the tracking of 2D and 3D structures of the beating heart in dynamic USI and $\mathrm{NMI}^{25}$

\section{D edges}

As previously mentioned, a major advantage of 3D images comes from the fact that intensity is usually a simple function of the structures studied (contrary to video images of a 3D scene). To segment CTI or MRI images, assuming constant intensity plus additive noise within a given anatomical structure is often a reasonable assumption in regions with low texture. Intensity in NMI images is also simply related to the physiological function studied, but the resolution is often lower with a higher noise level. The most difficult images to segment are probably USI, where intensity already measures a function of the derivative of the acoustic impedance of the tissues, but with a strong multiplicative (in frequency domain) noise producing a very typical 'speckle' texture almost everywhere.

For regions with low texture, Monga ${ }^{26,27}$ showed that the 3D generalization of the Deriche Canny edge operator $^{28}$ was quite efficient to extract edges. The superiority of $3 \mathrm{D}$ filtering the volumetric data instead of successively filtering 2D cross-sections was clearly demonstrated, as can be seen in Figure 4.

Because 3D filtering is computationally more intensive, the use of separable recursive filters is crucial for the sake of computational complexity. Malandain implemented a version of the 3D edge detector which has been distributed to several places.

\section{Digital topology and mathematical morphology}

Thresholding and/or edge detection must generally be followed by some 3D mathematical morphology 


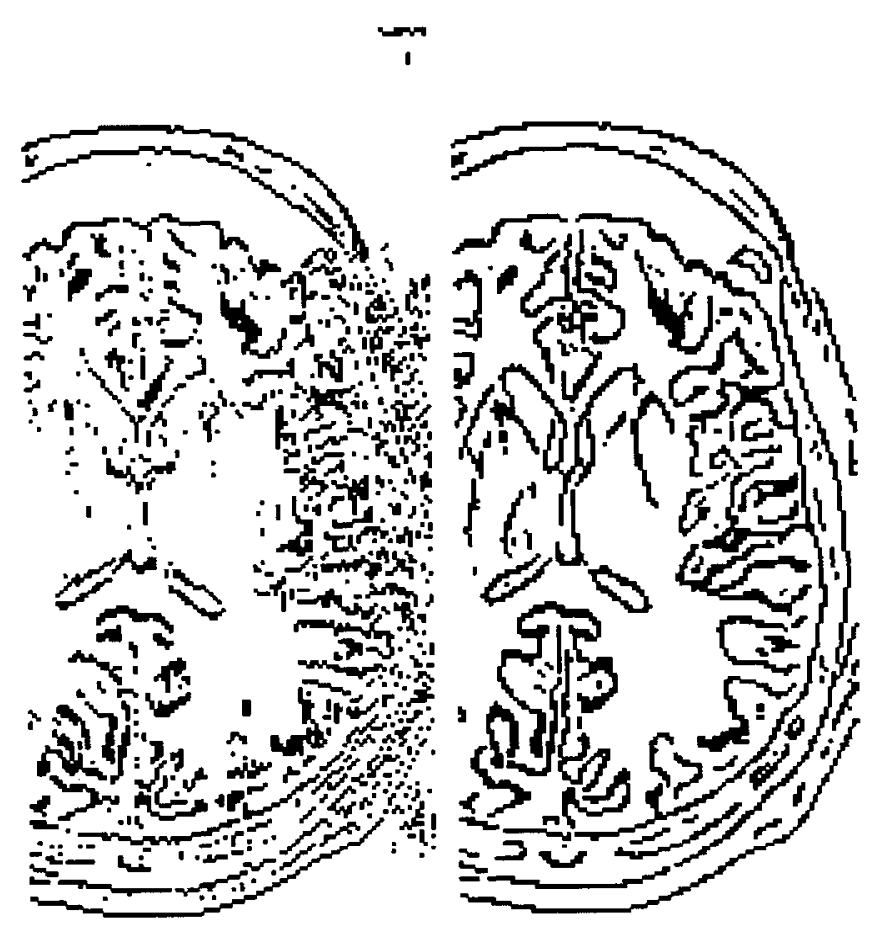

Figure $43 \mathrm{D}$ edge detection is more robust and coherent than 2D edge detection. I.eft: result of $2 \mathrm{D}$ edge detection performed in successive cross-sections of the brain which were orthogonal to the plane of the picture. Result from one cross-section to the next is not as coherent as it is with 3D edgc filtering (right), where none of the three principal directions is privileged (courtesy of Malandain and Monga)

operators (erosion, dilation, thinning, connected component analysis, etc.) to separate regions from one another. These operations require a formal analysis of the discrete notions of connectivity for points, curves, surfaces and volumes in 3D images. This is the purpose of digital topology 29,30 and mathematical morphology ${ }^{31}$, disciplines to which Malandain and Bertrant recently brought interesting new results and algorithms ${ }^{32.33}$. For instance, in Figure 5 they show the extraction of topological singularities on the surface of two skulls.

Recently, Kapur ${ }^{34}$ produced excellent results on the segmentation of the brain in MR images with mathematical morphology, and Wells ${ }^{35}$ showed how to suppress a multiplicative gain in the image field.

\section{Deformable surfaces}

This approach consists in generalizing in three dimensions the active contours introduced by Terzopoulos and coworkers ${ }^{36,37}$. A variational method has been developed by Laurent Cohen, and then by Isaac Cohen, to minimize an energy which accounts for the elasticity properties of the surface (internal energy) and the proximity of detected edgels (external energy). The mathematical framework is one of the finite elements, which provides a sound and stable analytical description of the surface. This approach provides a good segmentation of surfaces with a simple topology $y^{38-40}$.
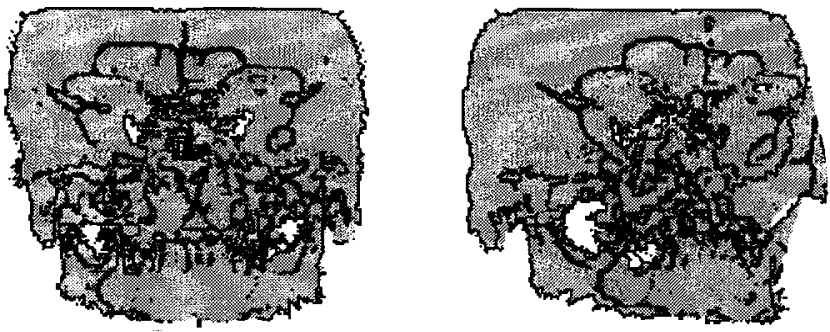

Figure 5 Extraction of topological singularities on the surface of two skulls. One should note the remarkable stahility of these lines, which can be used for registration (courtesy of Malandain and Bertrand)

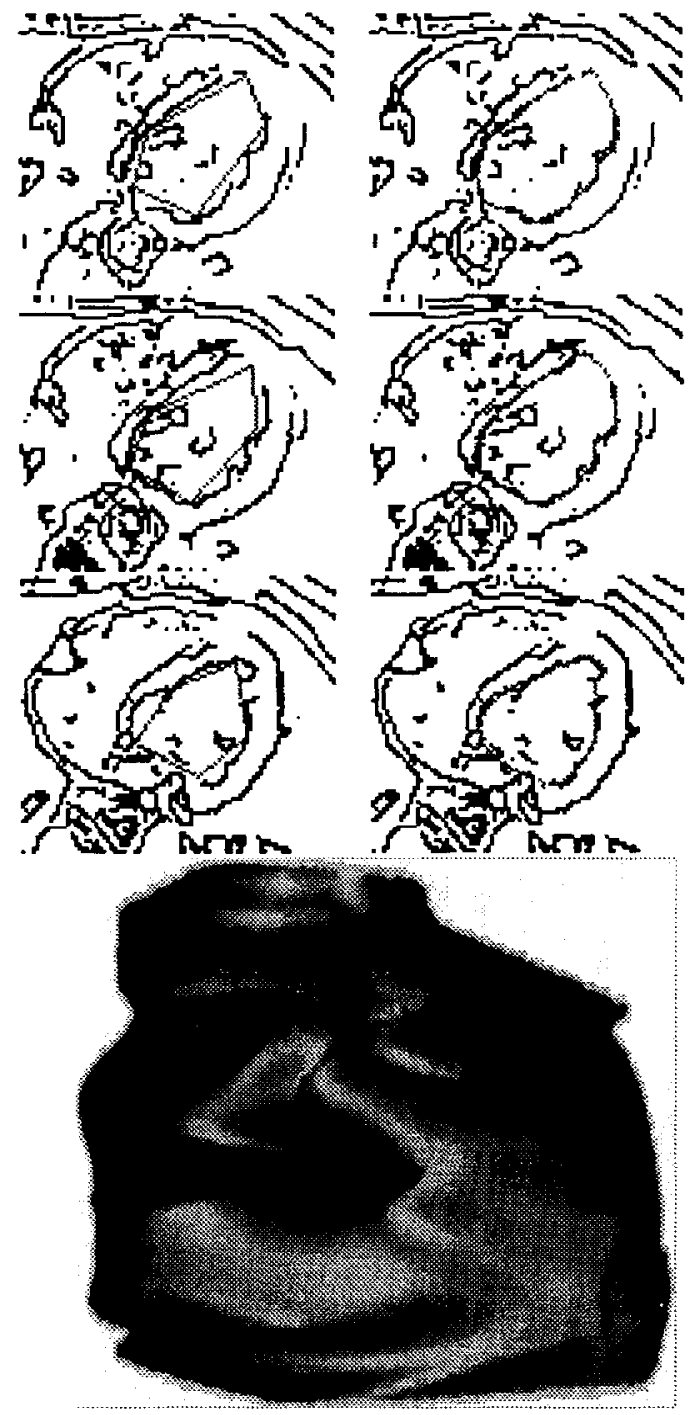

Figure 6 In this example, we used a deformable surface constrained by boundary conditions (cylinder type) to segment the inside cavity of the left ventricle. We show the initial estimation superposed in light grey in some cross-sections of the 3D image ( 1 st column), and the final solution (2nd column). Bottom: found 3D representation of the inside cavity of the left ventricle (courtesy of Cohen and Cohen)

We show in Figure 6 an example of the segmentation of a heart ventricle in a $3 \mathrm{D}$ image. After the segmentation of such a 3D image, deformable surfaces appear to be sufficiently robust to track a deformable structure in a time sequences of $3 \mathrm{D}$ images ${ }^{41}$. Connected work can be found elsewhere ${ }^{42-52}$. 


\section{Sonar space filtering}

In some cases, it might be interesting to perform the segmentation before $3 D$ image reconstruction, i.e. from the raw data obtained by the original sensor. This was clearly demonstrated for IUSI, with a method called sonar space filtering.

In USI, Herlin and Vojak showed that the polar geometry of USI requires a special type of filtering which computes edges at the local resolution of the raw data. This is important, because once the image is rectified from polar to cartesian coordinates, some information is lost, and the edge extraction results are degraded. Results obtained in time sequences of echographic images allow analysis of the motion of the mitral valve of the heart, with the help of the previous active contours, as shown in References 53 and 54. Similar results have also been obtained by Herlin et al. with Markov random fields ${ }^{55}$.

\section{Geometric tomography}

In the same spirit as above, but for CTI, Thirion showed that it was possible to extract the boundary of contrasted objects directly from the edges of the sinograms (projections from which lomography is computed). The advantage is a much faster extraction of the edges directly from the data acquired by an x-ray scanner, without requiring the costly tomographic reconstruction itself. The method, called geometric tomography, has been patented by INRIA ${ }^{56}$. It works particularly well with convex objects, as reported elsewhere $^{57}$.

\section{Texture-based approaches}

Lévy-Véhel, Berroir and Mignot ${ }^{58-60}$ implemented a system called ARTHUR, which combines texture modelling and a sophisticated discriminant analysis scheme to select a set of discriminant texture parameters from a training set of images (this approach has similarities with the work of Kubler and Gerig ${ }^{61}$ ). The ARTHUR system can then be connected to a texture segmentation program called EXCALIBUR, which exploits the training phase and the notion of 'mixed classes' to provide automatic segmentation of textured images. The texture operators include $2 \mathrm{D}$ and $3 \mathrm{D}$ texture operators; some of them involving advanced fractal and multifractal parameters. Figure 7 shows the result of such a textural segmentation in a cross-section of an MRI, at the level of the heart.

\section{MODELLING FREE-FORM SURFACES}

Once objects are segmented, they have to be modelled for further processing. This modelling is necessary for registration (next section), which is either rigid (some
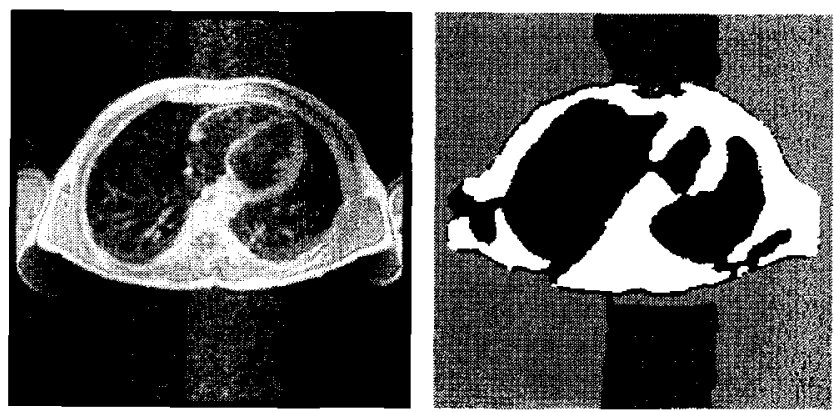

Figure 7 Left: MRI cross-section of the body at the level of the heart Right: segmentation result, obtained by EXCALIBUR, into four regions based on texture analysis (courtesy of Lévy-Véhel)

rigid part of a single patient) or deformable (nonrigid part of a single patient, or inter-patient or patient-atlas registration). This is a very challenging problem in medical image analysis, to study, for instance, the evolution of a pathology such as multiple sclerosis (MRI images), or the efficiency of a treatment against a cancer lesion (MRI or scanner images). This is also necessary to compare patients together and help therapy planning.

\section{Extracting ridges}

The approach successfully developed in the EPIDAURE project consists in extracting typical lines, called ridges or crest lines, on the surface of the objects in each volumetric image.

Our definition of ridges on a surface is the locus of points where the maximum curvature (in absolute value) is extremal in the direction of maximum curvature. This definition does not apply when principal curvatures have the same absolute value, in particular at umbilics. Anyhow, as can be seen from experimental studies (see below), these ridges convey intrinsic, meaningful and compact information on many anatomical surfaces:

- intrinsic, because ridge points are invariant with respect to rigid displacements (this comes from the intrinsic properties of the curvature);

- meaningful, because ridges tend to correspond to anatomical features (this is the case on the brain, the face and the skull, for instance, as can be seen in Figures 8,10 and 15, and also in References 62 67);

- compact, because they represent a number of points, typically 500 times more compact than the original image.

Several definitions of ridge or crest lines can be found ${ }^{68-74}$. The one closer to our definition is probably in the book by Hosaka ${ }^{75}$ (p. 98).

One should note that our definition of ridges is intrinsic to the isophote surface, without privileging any particular direction of the 3D space. One should refer to Koenderink ${ }^{76}$ for a rigorous and historical analysis of oriented ridges, i.e. ridges depending on a privileged dircetion in space (e.g. gravity). 
Computing curvatures requires the extraction of the differential properties of the surfaces up to the 2 nd order, while ridges require 3 rd order differential properties. We show in the following subsections the different approaches we investigated to achieve a reliable ridge line extraction.

\section{Local fitting of quadrics}

After a segmentation of the 3D images, using, for instance, 3D edge detectors, Monga and Sander showed that it was then possible to use a local Kalman filter around each edgel, to fit a quadric surface in the least square sense. This polynomial approximation allows the computation of differential surface properties up to second order only (curvatures). This approach takes into account the uncertainty attached to the edge localization and the surface normal, and provides an explicit estimation of the uncertainty attached to the computation of the principal curvatures. Unfortunately, although parallel in nature, the method is computationally very expensive. Curvature information is accurately extracted, but this is not the case for ridges ${ }^{77}$.

\section{Deriving the image intensity}

Another approach is necessary to extract ridges. As mentioned earlier, it is often a reasonable assumption to say that the boundary of an anatomical surface corresponds to an isophote (or iso-intensity) surface in the volume image, especially with CTI, but also with MRI and sometimes NMI. This assumption, combined with the implicit function theorem, allows the computation of the differential properties of the anatomical surface from the derivatives of the intensity function. This method provides excellent results in high resolution volumetric images, for a computational cost which can be maintained at a reasonable limit thanks to separable recursive filtering, as shown by Monga and Benayoun ${ }^{63,64}$ and Thirion ${ }^{65}$.

Figure 8 shows the extraction of ridges on the brain surface acquired with MRI, while Figure 15 shows the extraction of ridges on the surface of a skull acquired with CTI in two different positions.

The idea of deriving the intensity to extract different characteristic features, either on the intensity (hyper)surface or on isophote surfaces, is also successfully applied by (among others) Harr Romeny et al. ${ }^{71}$, Whitaker ${ }^{72}$ and Morse et al..$^{74}$.

\section{Using B-spline approximations}

The previously mentioned deformable surfaces had two drawbacks: high computational complexity, and loworder derivability. The introduction of B-splines with high order polynomials, thanks to their nice separability properties, reduces these drawbacks drastically while keeping the advantages of simultaneously providing a

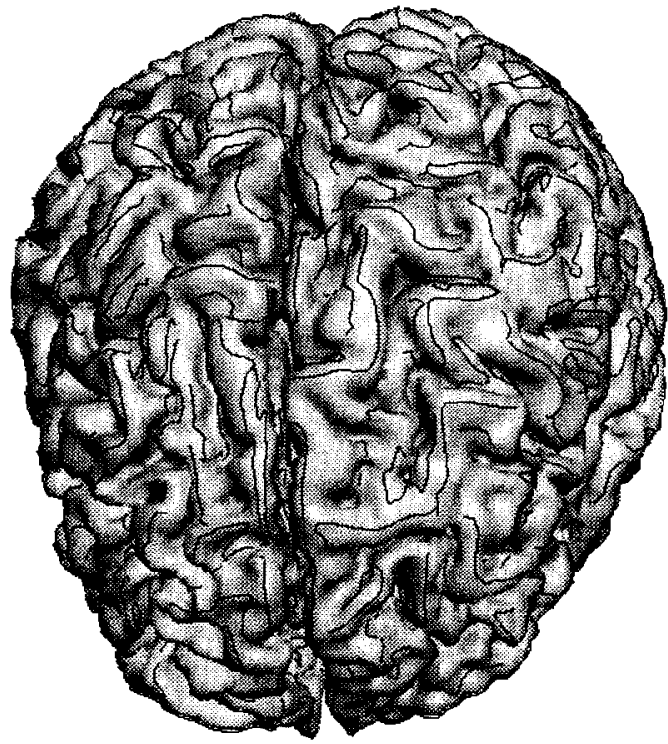

Figure 8 Ridges on the brain (courtesy of Thirion and Gourdon)

segmentation of anatomical surfaces and their local differential properties up to the third order, for instance. This is very useful to track time-varying structures with rigid or nonrigid motion. The only limitation comes from the fact that the surface topology must be known in advance. This is described in detail by Guéziec ${ }^{78,79}$.

Figure 9 shows the segmentation of a face with a deformable B-spline within an image of the head acquired with MRI, while Figure 10 shows the extraction of ridges obtained from the B-spline approximation.

\section{Marching line algorithm}

In the two previous approaches (filtering and B-splines), the connection of extracted ridge points to form ridges can be achieved by a very smart algorithm invented by Thirion, and called 'the marching line algorithm'. This algorithm looks for the zero-crossings of an extremality criterion (here the maximum curvature) in an isophote surface defined by a constant intensity level $I$. The algorithm ensures both sub-pixel accuracy and nice topological properties like connectivity and closeness. Also, it can be applied simultaneously with the local filtering of isophote surfaces, to drastically reduce the filtering computing time if one seeks the extraction of major ridges only. A complete description of this algorithm can be found elsewhere ${ }^{65,80}$. The ridges of Figures 8,10 and 15 were extracted with the marching line algorithm.

\section{RIGID 3D REGISTRATION}

I now describe in more detail the problem of rigid $3 \mathrm{D}$ registration, because we believe it is a remarkable illustration of computer vision applied to $3 \mathrm{D}$ medical images. 


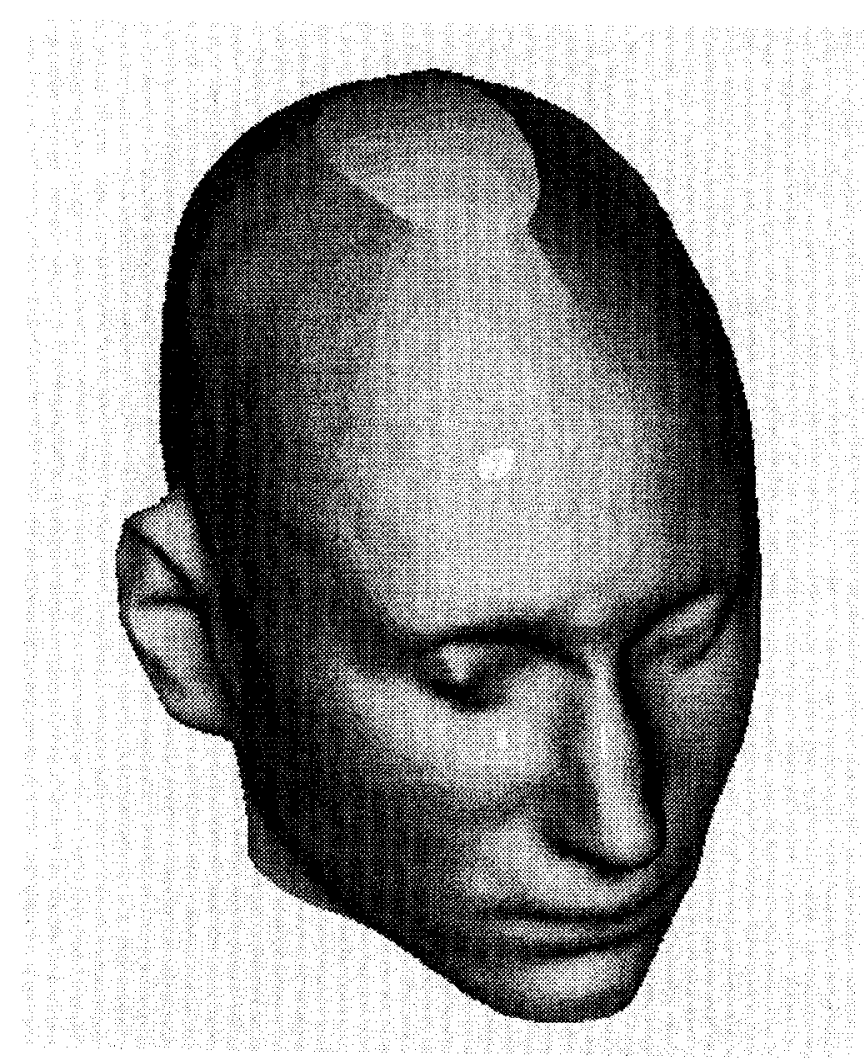

Figure 9 Segmentation of a face with a deformable B-spline within an image of the head acquired with MRI. Original MRI images were provided by Dr Ericke, Siemens (courtesy of A Guéziec)

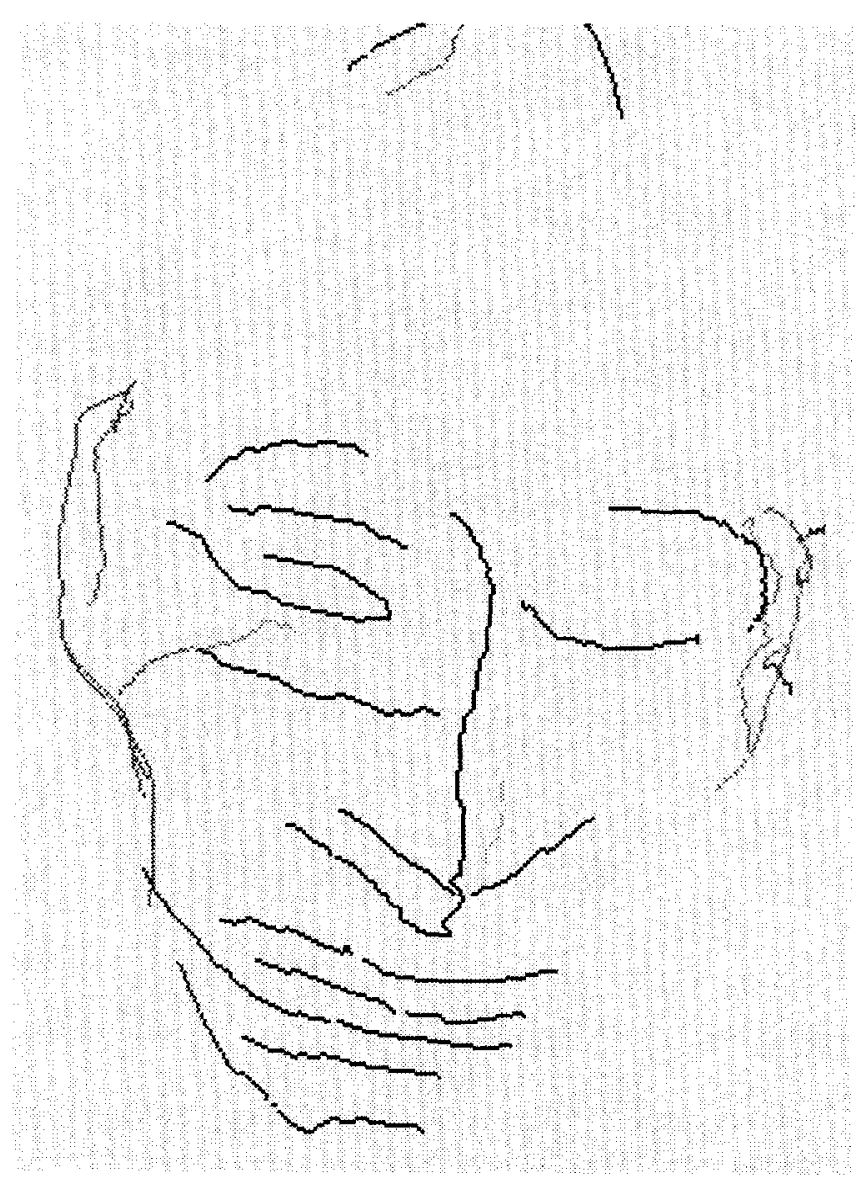

Figure 10 Ridges extracted from the previous B-spline approximation (courtesy of A Guéziec)

\section{Importance of the problem}

As mentioned before, a very common problem in medical image analysis is the automatic registration of $3 \mathrm{D}$ images of the same patient taken at different times, and in different positions. This is very useful to detect any pathological evolution, and to compute quantitative measurements of this evolution.

Performing this registration manually is a difficult task for a human operator, mainly because it requires quantitative spatial reasoning. The operator must discover corresponding anatomical landmarks, and locate them in $3 \mathrm{D}$ with maximum accuracy. As the accuracy of the computed global registration increases with the number of matched correspondences, it is preferable to match as many landmarks as possible. Performing this task manually for tens of landmarks is extremely tedious, and it becomes infeasible with hundreds or thousands of landmarks.

Artificial landmarks could be used to simplify the point extraction and matching process. For instance, a stereotaxic frame can be rigidly attached to the patient's skull. In fact, this is not a very comfortable solution for the patient, and anyway, such a frame cannot be worn for a long period (e.g. six months!). Moreover, it can happen that some displacement occurs between the frame and the patient between the two acquisitions, or that some internal organ moves with respect to the external frame (e.g. a slight motion of the brain with respect to the skull). Finally, the accurate localization of specific points with artificial markers is usually not an obvious task.

For all these reasons, we believe that a fully automatic registration procedure relying only on detected anatomical landmarks is much more flexible and powerful than a manual procedure, or than a procedure relying on artificial landmarks.

The output of the registration procedure must be the six independent parameters of the rigid displacement undergone by the region of interest between the two acquisitions. More precisely, one must compute the rotation and translation parameters which best match the two acquired images of this region of interest. At this point, it is important to note that because of potential occlusions, the two 3D images cannot be registered globally with a method based on the registration of the centres and axes of inertia.

\section{Using ridges and geometric hashing}

The idea is to extract the maximum number of Euclidean invariants computed exclusively on ridges, and to use them for registration.

\section{Euclidean invariants on surface curves}

We consider not only the curvature $k$ and torsion $\tau$ of the ridge lines (the parameters which characterize completely a curve up to a rigid displacement), but also the maximum curvature of the surface, $k_{1}$, the angle $\theta$ 


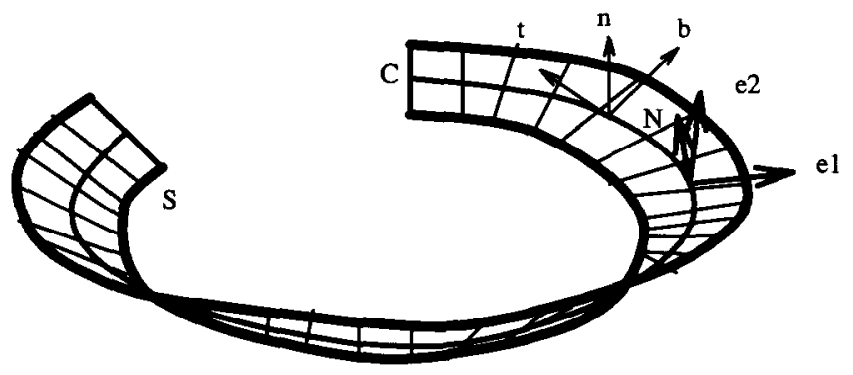

Figure 11 Surface ribbon around a space curve: at each curve point, one can compute the curve Frenet frame $(t, n, b)$, where $t$ and $n$ are, respectively, the curve tangent and normal, and the local surface frame $\left(e_{1}, e_{2}, N\right)$, where $e_{1}$ and $e_{2}$ are the principal directions of curvatures in the tangent plane of the surface, and $N$ the surface normal (courtesy of A Guéziec)

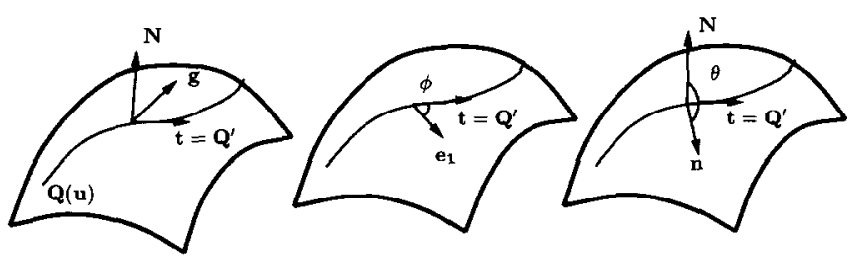

Figure 12 Left: Darboux frame $(t, N, g)$ computed along the ridge line, on the surface. Centre: $\phi$ is the angle between the direction $e_{1}$ of the largest principal curvature $k_{1}$ with $t$. Right: $\theta$ is the angle between the curve normal $n$ and the surface normal $N$ (courtesy of Guéziec)

between curve and surface normals, and the angle $\phi$ between the curve tangent and the direction of the maximum curvature $k_{1}$ (see Figures 11 and 12). These five intrinsic parameters are independent, and allow, for instance, the computation of the second principal curvature of the surface through computation of the normal curvature $k_{n}$, as well as the geodesic curvature $k_{g}$ and torsion $\tau_{g}$ of the surface.

As the extraction of the ridge points required the computation of differential properties of the surface up to the $3 \mathrm{rd}$ order, the values of the maximum curvature value $k_{1}$ and direction $e_{1}$, as well as the surface normal $N$, are readily available. But to compute the five intrinsic parameters $\left(k, \tau, k_{1}, \theta, \phi\right)$, we also need to compute the differential properties of the curve itself up to the 3rd order. Guéziec found that an efficient method was to approximate each ridge line (a discrete set of ridge points connected by the marching line algorithm) by a constrained B-spline ${ }^{81}$ (the B-spline is constrained to have a tangent orthogonal to the surface normal). This provides a good estimation of the Frenet frame of the curve, $(t, n, b)$, as well as the local curvature $k$ and torsion $\tau$. It is then immediate to compute $\theta=\operatorname{angle}(n, N)$ and $\phi=\operatorname{angle}\left(t, e_{1}\right)$.

\section{Matching algorithm}

Once we know how to extract ridge points and how to compute the quantities $\left(k, \tau, k_{1}, \theta, \phi\right)$ at each ridge point, it is possible to design an extremely efficient matching algorithm. This algorithm, proposed by Guéziec, has two main stages, namely preprocessing and recognition, and combines geometric hashing, accumulation and prediction-verification ${ }^{82} 89$ :

- Preprocessing stage This stage can be applied offline, as soon as the first image, called the model image, is acquired. The ridge lines are extracted from this image, and each ridge point with its Frenet frame $(t, n, b)$ is stored in a 5-dimensional hash table based on the five intrinsic parameters $\left(k, \tau, k_{1}, \theta, \phi\right)$ attached to the ridge point

The 5-dimension hash table is stored in a 1dimensional array using classical but efficient hashing techniques (see Figure 13).

- Recognition stage Once the second image, called

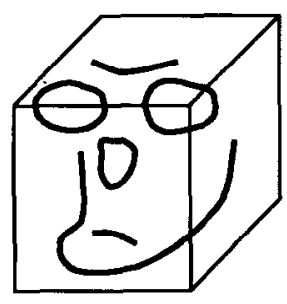

Real Space Model Curves

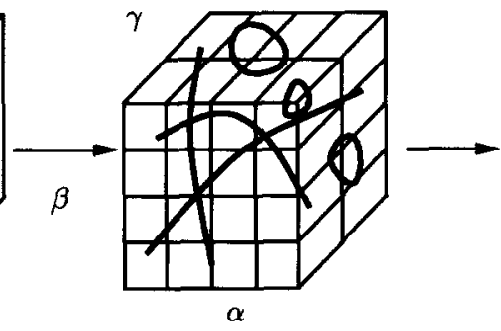

Parameter (Hash)-Space

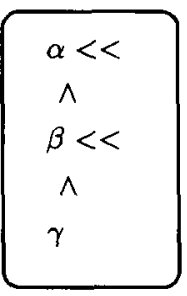

Hash Function

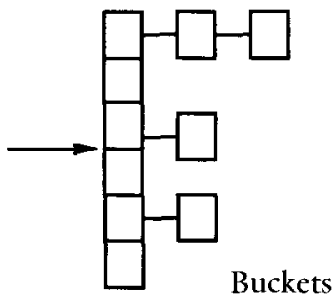

H-Table

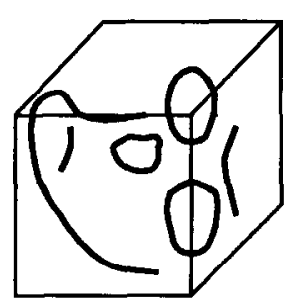

Scene Curves

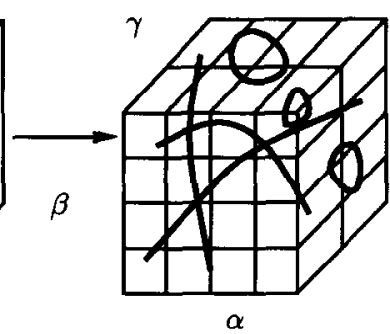

Figure 13 Preprocessing: each ridge point of the model, is stored in a hash table of dimension-5, after the computation of five independent intrinsic parameters. At recognition time, the same ridge point, although in another position and orientation, will point towards the same cell of the hash table (courtesy of Guéziec) 
the scene image, is acquired, it is necessary to apply the recognition stage on-line. The algorithm considers each ridge point $S_{i}$ of the scene, and looks in the hash table for a model point with similar intrinsic parameters $\left(k, \tau, k_{1}, \theta, \phi\right)$. A difficult point is the notion of similarity, and a preliminary statistical study allowed for the definition of a statistical distance (Mahalanobis distance) based on the covariances of these parameters.

If a model point $M_{j}$ is found with similar parameters in the hash table, the Frenet frames of both points are used to predict a rigid transformation $T$ which maps both points with their Frenet frames (see Figure 14). This transformation is accumulated in a 6-dimension accumulator of rigid transformations $\mathcal{A}$, by incrementing the cell whose coordinates correspond to $T$, and by keeping a pointer towards $M_{j}$ and $S_{i}$. The uncertainty attached to the position of $M_{j}$ and $S_{i}$ is represented by two covariance matrices, which are used to compute a covariance matrix $\Sigma$, which represents the uncertainty on $T$.

When the accumulator cell already contains a rigid transformation $T^{-}$and a covariance $\Sigma^{-}$, both are updated with a recursive least square procedure (the extended Kalman filter), and a new value $T^{+}$is stored, with a new covariance matrix $\Sigma^{+85}$.

When all scene points have been treated, the algorithm looks for the accumulator cell which had

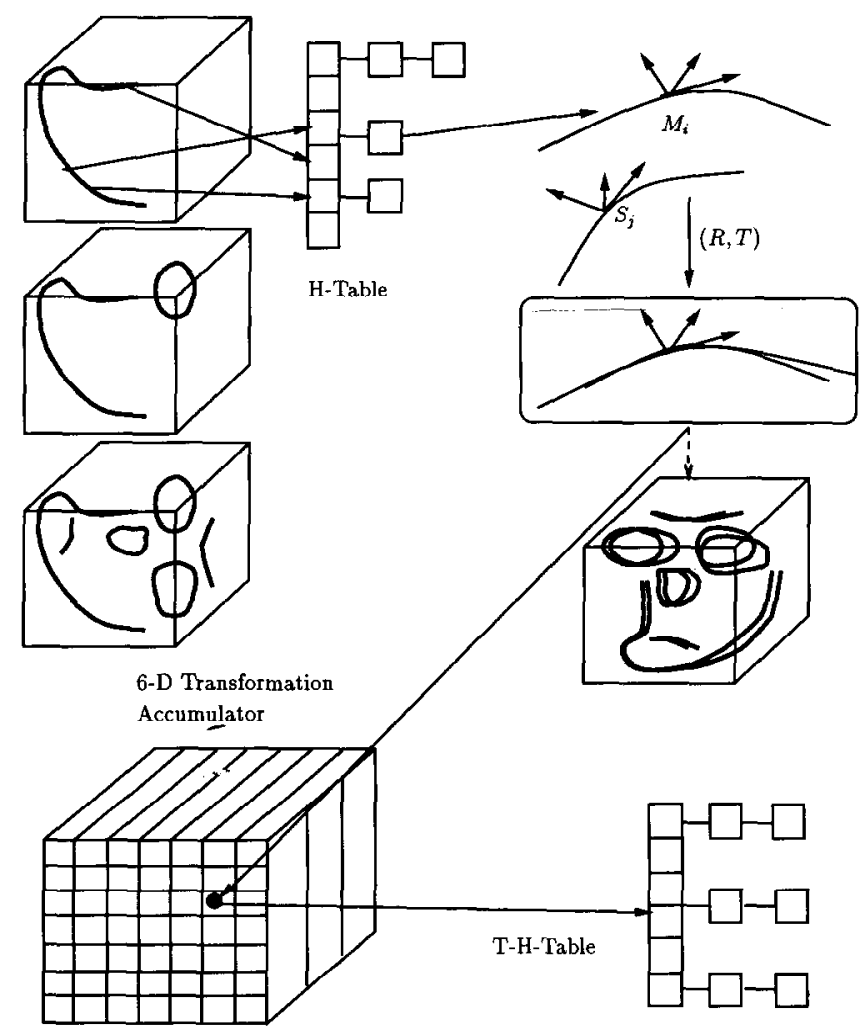

Figure 14 Recognition: each time a ridge point of the scene is matched with a model point through the previous hash table, the Frenet frames allow the computation of the six parameters of a rigid displacement $(R, t)$. This displacement is stored in a 6-dimension accumulator, which is stored with another Hash table (courtesy of Guéziec) the maximum number of access. This cell contains a transformation $T^{*}$ with a covariance matrix $\Sigma^{*}$, and it is chosen as being the solution of the registration problem.

In the skull example presented, this transformation corresponds to the matching of 335 couples of ridge points. We can apply this transformation to all the ridge points of the model, and verify that they superimpose very nicely on the scene ridge points, as can be seen in Figure 16. A quantitative analysis showed that the accuracy of the registration was better than one millimeter within the volume of the head $^{90}$.

\section{Matching of proteins}

Pennec found that it was possible to extend the geometric hashing ideas to the problem of finding common 3D substructures in proteins. He found an $O\left(n^{2}\right)$ algorithm ${ }^{91}$. A typical result is shown in Figure 17.

\section{Introduction of extremal points and extremal mesh}

Thirion $^{92,93}$ recently introduced a new subset of intrinsic points that he called 'extremal points', which
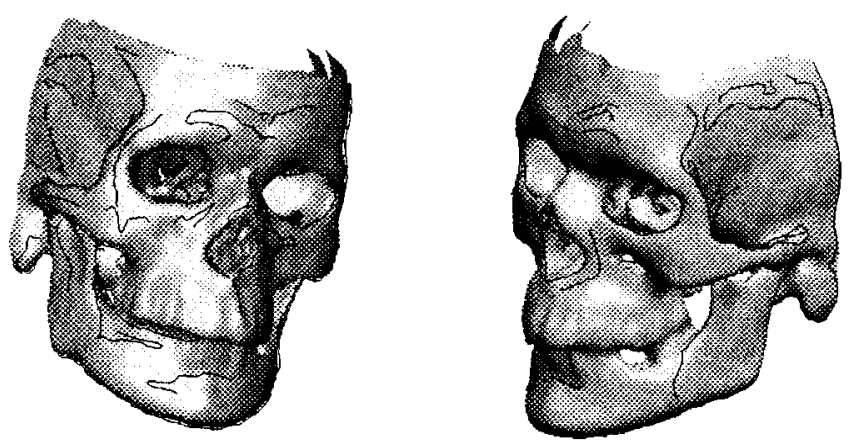

Figure 15 Top: Ridges (in black) extracted on the surface of a skull scanned in two different positions (left and right). Original 3D images are produced by a GE-CGR CT-Scan (courtesy of Thirion and Gourdon)

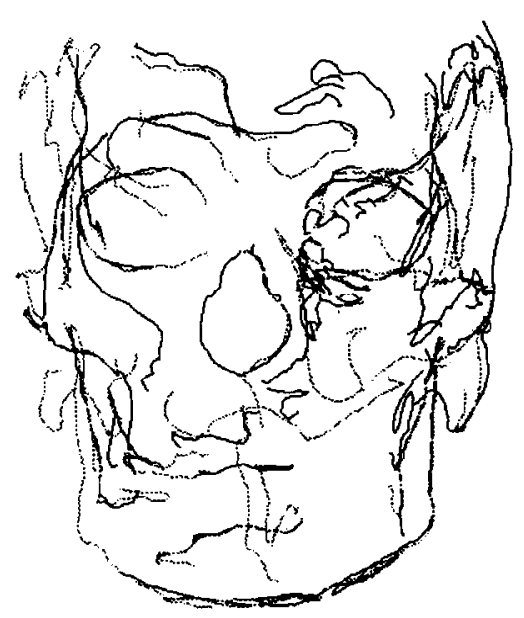

Figure 16 Automatic registration of the two sets of ridge lines (respectively, solid and dotted lines), allowing a sub-voxel comparison of the two original 3D images (courtesy of Guéziec) 

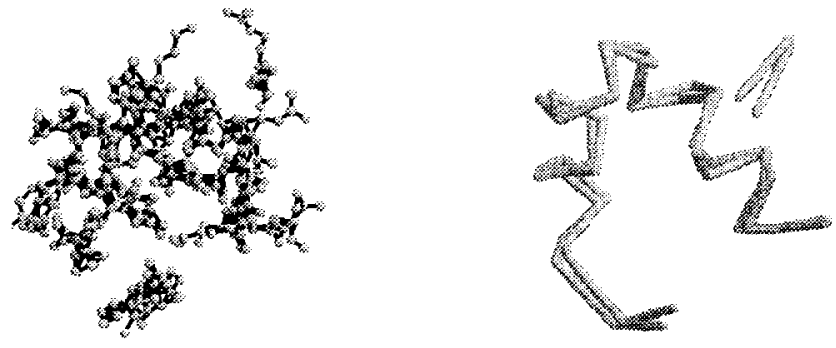

2 CKO (63 amino-acids) and $2 W R P$ ( 108 amino-acids). Unly registered structures are shown, i.e. 27 amino-acids. The right picture is a synthetic representation of the proteins skeletons (courtesy of Pennec)

can be identified as the subset of ridge points for which the second principal curvature $k_{2}$ is also extremal in the associated direction $e_{2}$. These points have the nice property of being extrema of curvature of the two principal curvatures simultaneously, and can be defined as the intersection of three iso-surfaces: a chosen isointensity surface, and the two surfaces defined by the zero-crossings of the derivatives of $k_{i}$ in the direction $e_{i}$ for $i=1,2$. These derivatives can be computed everywhere but at points where the principal curvatures have identical absolute values, which again includes the umbilics.

Not only the extremal points have the property of being very stable and compact on anatomical surfaces (a few hundreds in a high resolution 3D image of the head), but some of them tend to be extremely stable from one paticnt to another onc. They are, therefore, very good candidates as anatomical features for the $\Lambda$ tlas Matching Problem, described in a later section.

Finally, a unifying description, called the extremal mesh, which includes ridge lines and extremal points, haas also been introduced by Thirion ${ }^{94,95}$. This description is based on the zero-crossings of the product of two extremality criterions, defined at non-umbilic points as the derivative of one of the two principal curvatures in its associated direction. The product of these two criteria is clearly zero along ridge lines, and also at extremal points, and the definition naturally provides an intrinsic mesh on the surface, which itself proves extremely useful for its description, and also for rigid and non-rigid registration.

\section{Matching a cross-section with a $3 \mathrm{D}$ image}

Another interesting problem is the matching of a crosssection with a $3 \mathrm{D}$ image. This happens when the patient must be registered with previously acquired 3D images, during surgery, for instance. In this case only a few (possibly a single) cross-sections are acquired with a given modality, possibly with a laser range finder, and have to be matched with a surface extracted from a $3 \mathrm{D}$ image.

Gourdon showed that it was possible to exploit differential geometry constraints between the curve and
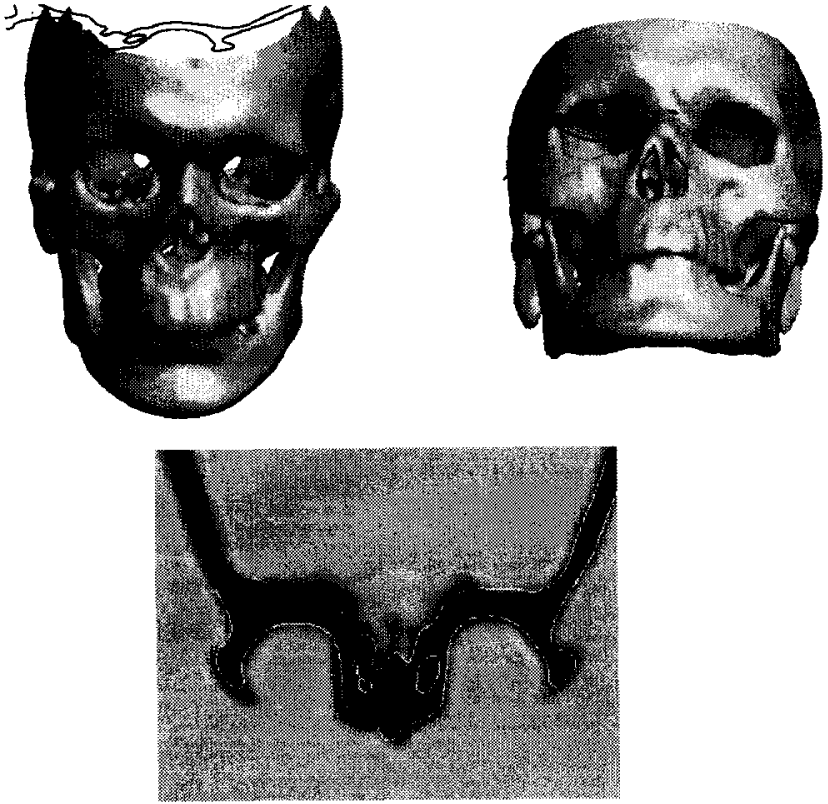

Figure 18 Left: a surface is extracted from a 3D CTI image and a curve is extracted from another $2 \mathrm{D}$ cross-section. Right: the curve is matched on the surface with the use of differential geometry constraints. Bottom: superposition of the curve in the image plane extracted from the 3D image (courtesy of Gourdon)

the surface to efficiently guide the correspondence algorithm ${ }^{96}$. A typical result is shown in Figure 18.

\section{Matching with a potential-based method}

Computing ridges and Euclidean invariants of second and third order requires high resolution images. This is currently not possible with NMI. Therefore, in this case, and in particular to combine together images of different modality like NMI and MRI, for instance, other methods, usually based on potentials of attractions, can be used efficiently ${ }^{97-103}$. Contrary to the method described in the previous section, based on geometric hashing and Euclidean invariants, potentialbased methods require a preliminary estimation of the correct superposition, which might sometimes limit their robustness. Anyhow, excellent results can be obtained, as shown in Figure 19, extracted from Malandain's and Rocchisani's ${ }^{97}$ work

\section{DEFORMATIONS}

Relaxing the rigidity assumption is necessary in three different problems: the atlas-matching problem; interpatient registration; and the analysis of nonrigid motion.

\section{Atlas matching problem}

Building an 'electronic atlas' of the human body is again a very challenging issuc for the futurc, and scveral teams 

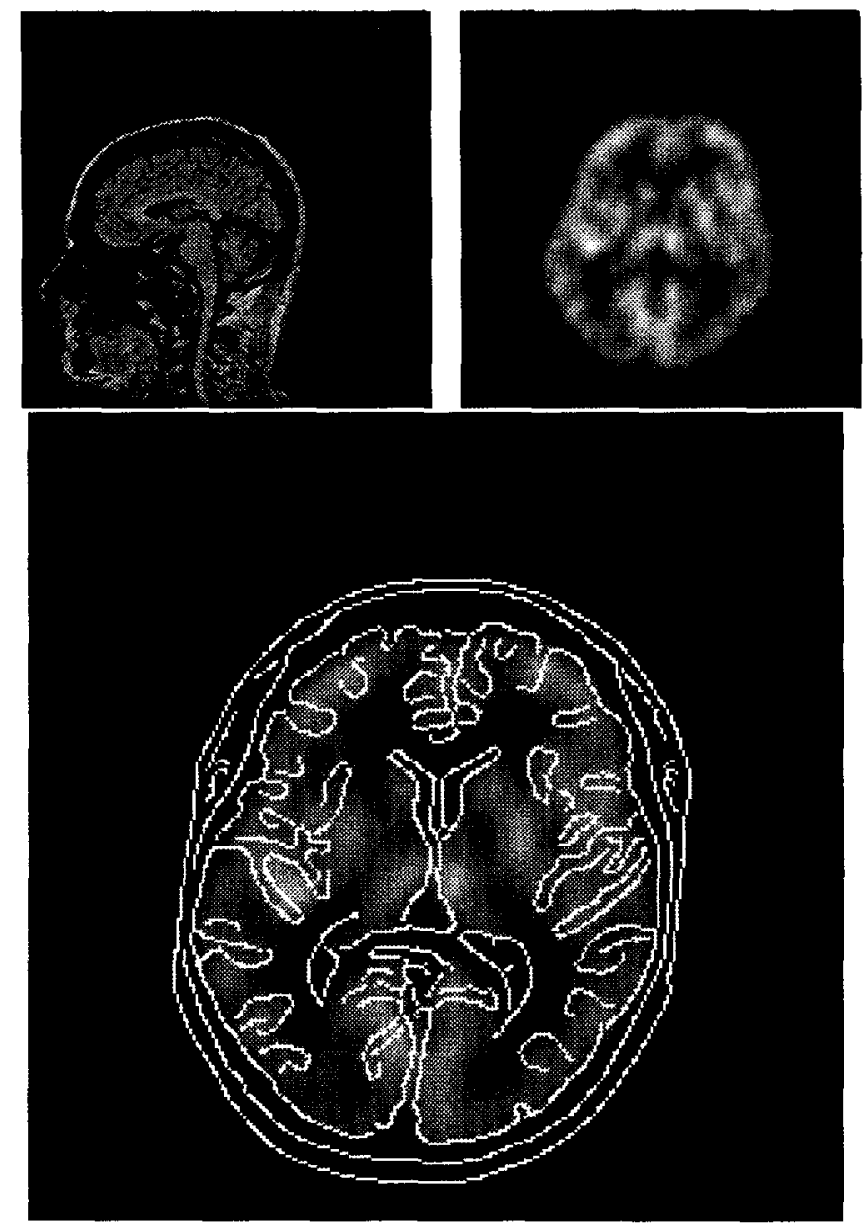

Figure 19 A potential-based method allows the registration of an MRI image (top left) with an NMI image of the head (top right). An interpolated cross-section of the registered 3D MRI is computed, and its edges are shown superimposed on the NMI images (bottom). Images are courtesy of Jael Travere, from the Cyceron Center in Caen, France (courtesy of Malandain and Rocchisani)

have contributed to this topic. Among them, one must acknowledge the pioneering work of Bajcsy et al. ${ }^{104}$ more than ten years ago!

Some recent work, like that of Hohne et al. ${ }^{105}$, is more oriented towards the construction of a visualization database. Our goal is oriented towards the automatic registration of such an atlas against the $3 \mathrm{D}$ image of an arbitrary patient. For doing this, we believe that ridge lines are good anatomical invariants, and can therefore serve as a sound geometrical basis to build a computerized anatomical atlas of some parts of the human body. This assumption is supported by our experimental studies, and by statistical and anthropological studies ${ }^{66,67}$.

Having built a 'generic model', the problem is then to find a matching algorithm which can register it with the 3D image of an arbitrary patient. Such an algorithm could also help in making inter-patient registrations and comparisons.

The current strategy within the EPIDAURE project, is to define a constrained network of ridge lines and extremal points ${ }^{92,93,106}$, which could deform itself to adapt to the geometry of a given patient. The spirit is
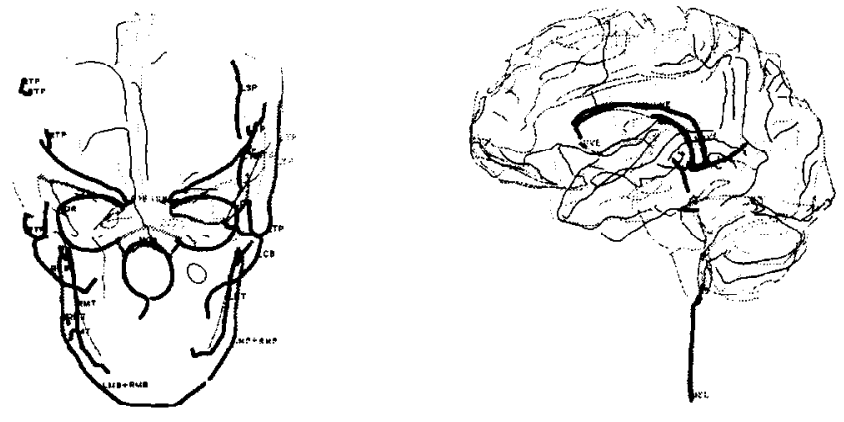

Figure 20 It is possible to use an average representation of the ridge ines to define an 'atlas of ridges", on a skull and on a brain. Then, this atlas can be used to automatically label the most stable lines of an arbitrary skull (left) or brain (right) (courtesy of Subsol and Thirion)

similar to that introduced by Yuille et al. ${ }^{107}$. Having natched this subset of characteristic lines and points, it should be possible to obtain registration everywhere, by ıpplying, for instance, a constrained interpolation with B-splines ${ }^{108,109}$. This is presented in Reference 110 .

The ideas of Cootes et al. ${ }^{111}$, who take advantage of a rincipal components analysis of a training data set to :onstrain the deformation of the model, could certainly se applied fruitfully.

We show in Figure 20 a preliminary result of the natching of a skull atlas on a 3D CT image of a patient.

\section{nter-patient registration problem}

To register together anatomical surfaces extracted from two different patients, Feldmar introduced a quite successful approach. He proposes to use curvature information on the two surfaces to successively find the best rigid, then globally affine, then locally affine transformation. The curvature information appears to be essential to preserve the correspondance between anatomical invariants, e.g. the nose, the chin, the eyebrows ... on a face. A typical example is shown in Figure 21. Details of this approach can be found elsewhere ${ }^{12-114}$. Another approach, also quite successful, was published by Szeliski and Lavallee ${ }^{115}$.

\section{Analysing nonrigid motion}

In time sequences of 3D images, like USI, MRI or NMI images of the beating heart, it would be extremely profitable not only to track the motion of moving structures, but also to provide physicians with a reduced set of pertinent parameters which describe their nonrigid motion. Usually, the problem is dual: first, it is necessary to find the motion of individual points; then it is necessary to approximate this motion with a reduced number of parameters.

\section{Motion of individual points}

Tracking structures with deformable models like snakes does not usually provide the motion of each individual 


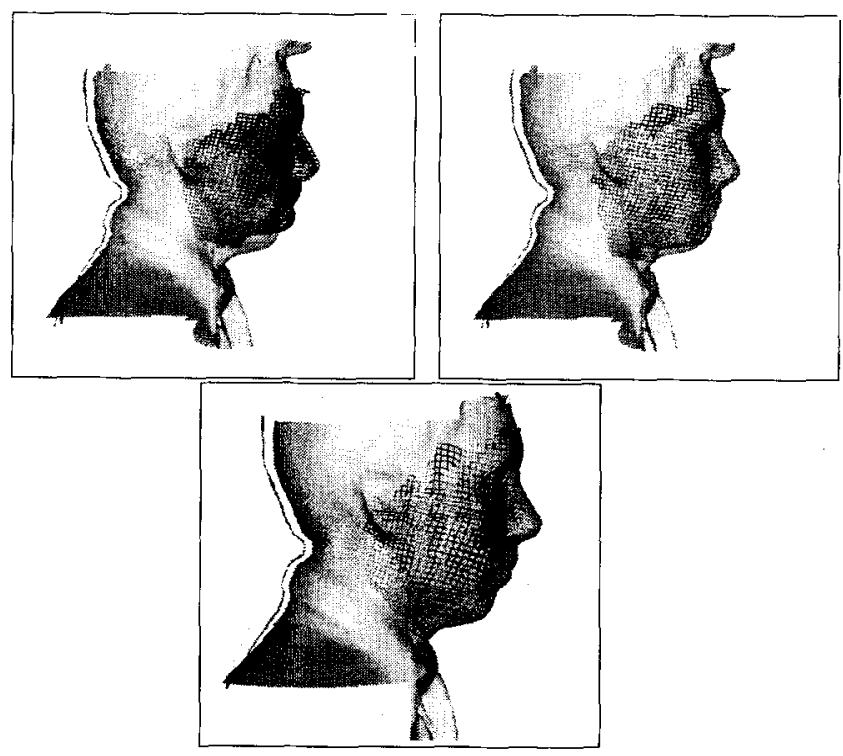

Figure 21 Inter-patient registration. Left: best rigid; centre: best affine; right: best locally affine. All these transformations tend to preserve the correspondence between regions of high curvature, and take into account the local modification of the curvature through an affine transformation. By this approach, the result preserves anatomical invariants based on curvature extrema (courtesy of Feldmar)

point, but only a global registration of a curve (or surface) against a curve (or surface). A post-processing, which takes into account the presence of geometric singularities along the tracked structures, and in particular curvature singularities, can be used to find point-to-point correspondences ${ }^{52,116-123}$. A typical result in $2 \mathrm{D}$, obtained with a finite element technique, is shown in Figure 22. The method has been implemented in 3D, and experimented on the scanner images of the Mayo Clinic (Courtesy of Dr R Robb), to
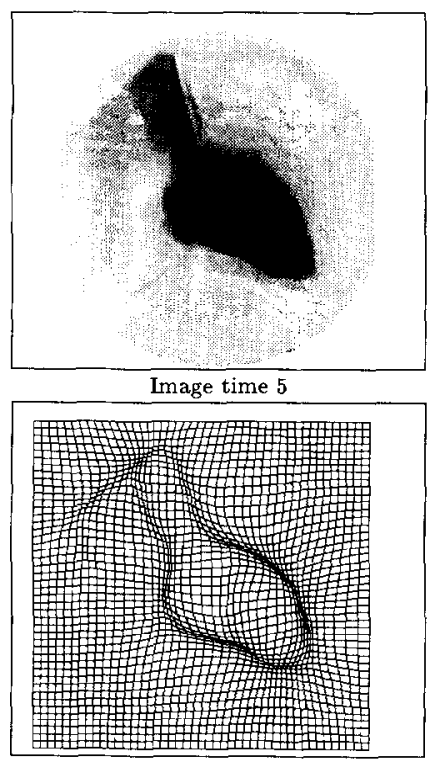

Adapted Mesh

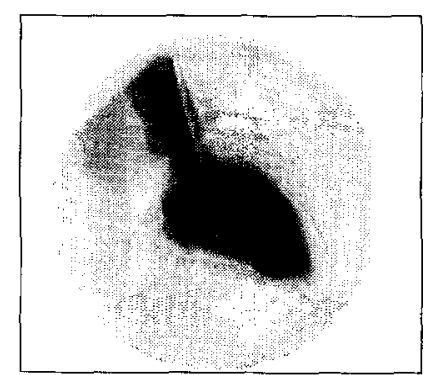

Image time 6

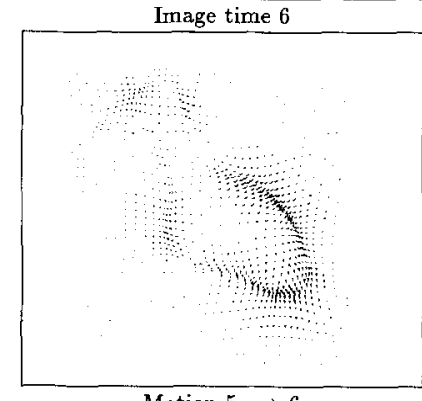

Motion $5 \Rightarrow 6$
Figure 22 Computation of the motion field between two successive images in a time sequence of $2 \mathrm{D}$ angiographies of the beating heart (courtesy of Benayoun) provide the motion field of the left ventricle during the systolic stage as shown in Figure 26.

Good results can also be obtained with a physicallybased deformable model which provides tracking and point-to-point correspondences at the same time ${ }^{124,125}$. Figure 23 shows the use of the deformable model of Nastar to track the mitral valve in images of the heart acquired with USI, and get point-to-point co:respondences.

\section{Global analysis of motion}

Once point-to-point correspondences have been established, it is possible to project on a reduced basis the set of displacements. This is the purpose of modal analysis, where the basis corresponds to a reduced se of some
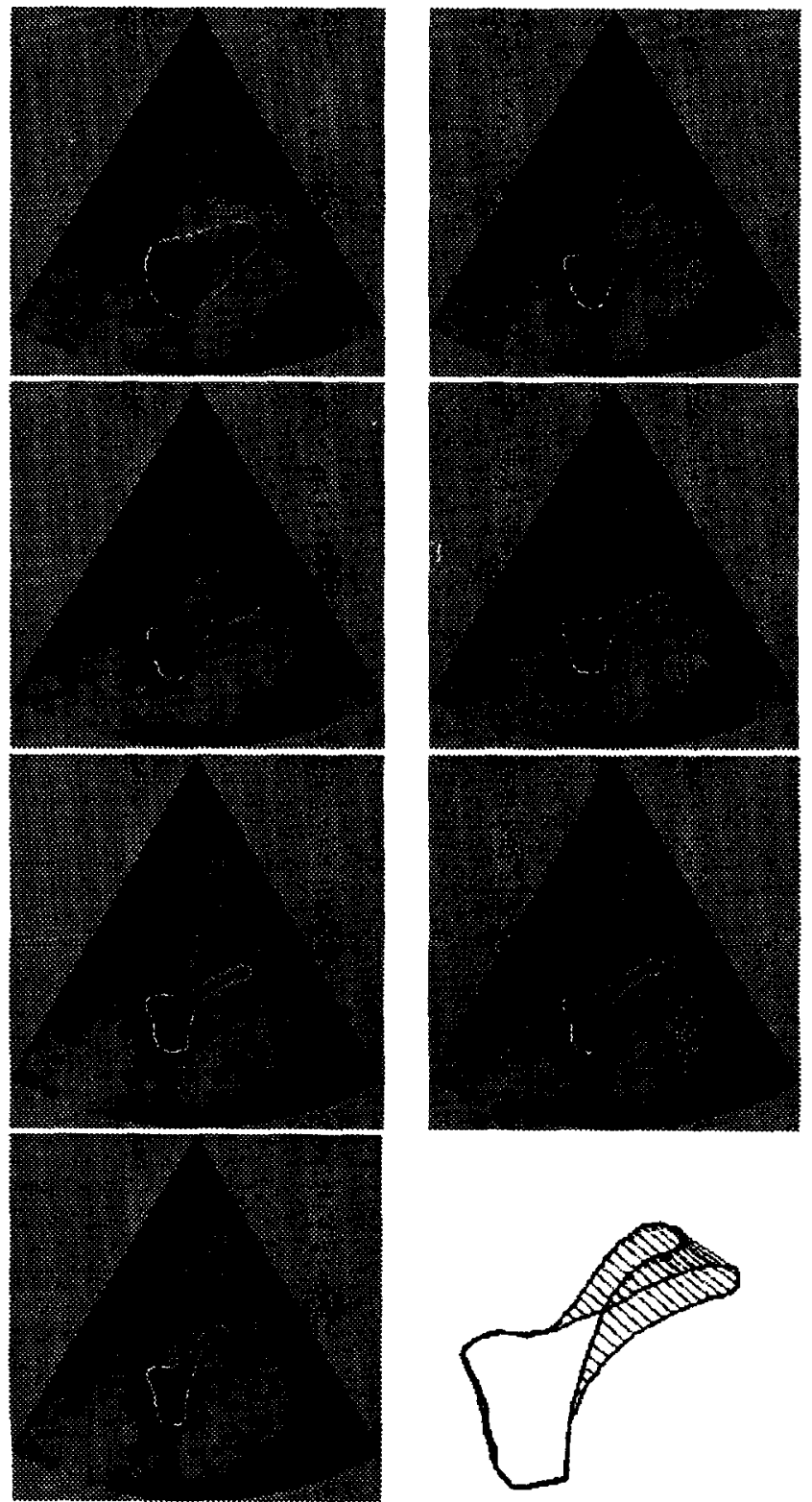

Figure 23 From left to right and top to bottom. (a) (b) Segmentation and $(\mathrm{c}-\mathrm{g})$ tracking of the mitral valve of the heart in a sequence of USI using the active physical model of Nastar; ( $g$ ) point-to-point correspondences obtained. These images were preprocessed with the sonar-space filtering method of Herlin referenced in the text (courtesy of Nastar) 
Figure 24 Energy-increasing vibration modes of a cylinder
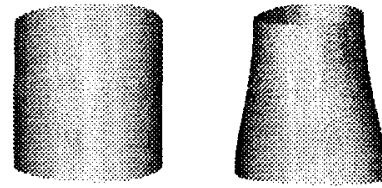

'qualitative' deformations ${ }^{126,127}$, or to the major monofrequency vibration harmonics of the elastic structure ${ }^{124}$ (see Figure 24 for an illustrative example of the principal encrgy-increasing vibration modes of a cylinder).

A major advantage of the latest approach is the possibility to compute analytically ${ }^{128}$ the modes beforehand, which reduces tremendously the computational complexity. Figure 25 shows a modal approximation of the 2D motion of the mitral valve shown in Figure 23, while Nastar showed that the motion field of the surface of the 3D ventricle shown in Figure 27 could be approximated with only nine principal modes and five
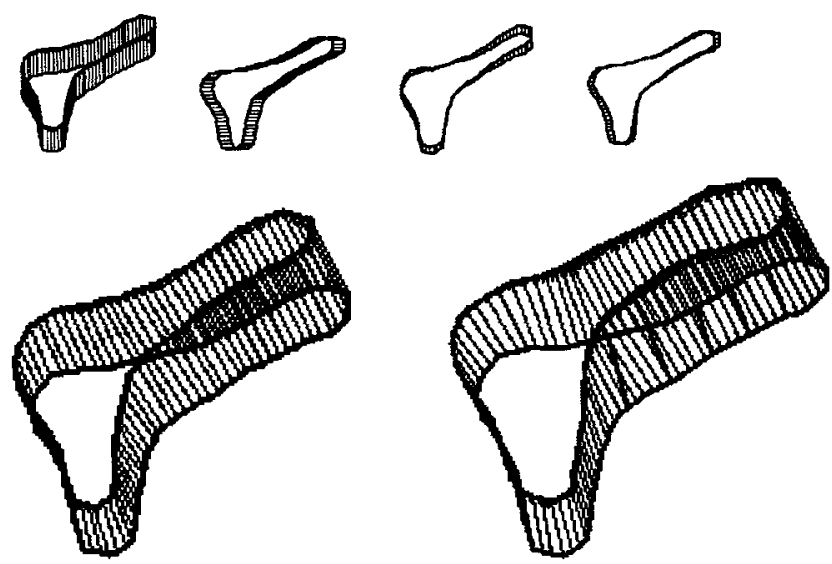

Figure 25 From left to right and top to bottom. Four high amplitude eigenmodes of the valve $(a, b, c, d)$. Their superposition (e) compared to the expected result (f) (courtesy of Nastar)

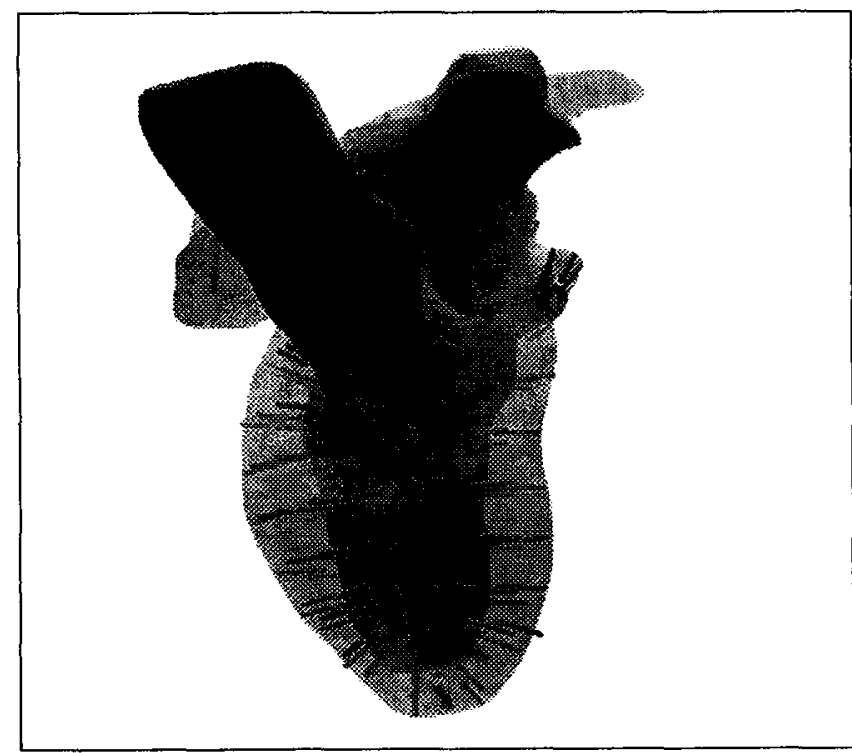

Figure 26 Computation of the motion field computed through a time sequence of 3D CT-scan images of the left ventricle during the systolic stage, using a finite element technique (courtesy of Benayoun). (Original CT images are a courtesy of Dr R Robb, Mayo Clinic)
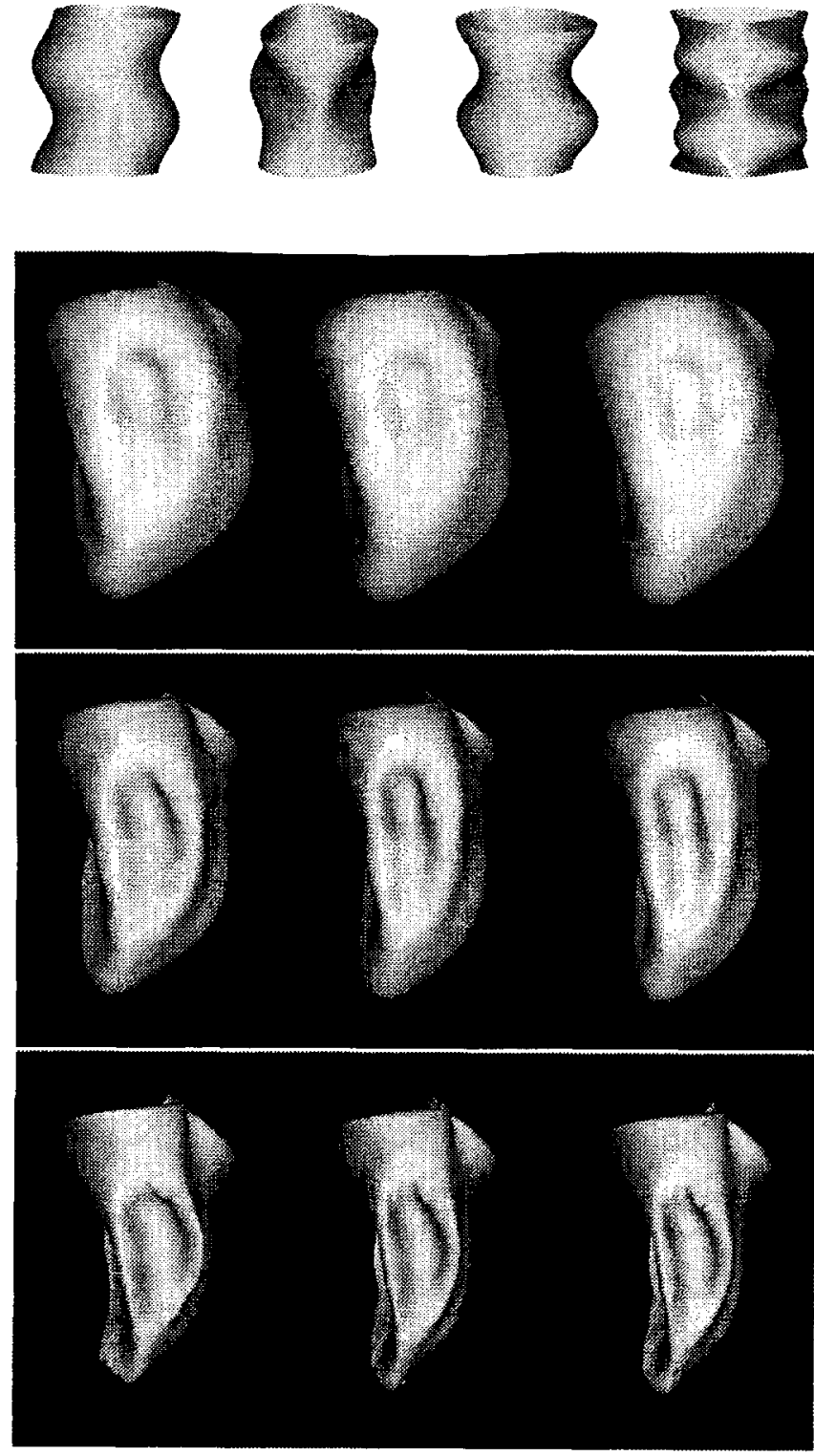

Figure 27 Spatio-temporal evolution of left ventricle. Left: original ventricle data consist of 18 temporal images of size $98 \times 100 \times 110$ (courtesy of Dr R Robb, Mayo Clinic); centre: synthesized motion with nine principal modes and 18 temporal values per mode; right: synthesized motion with nine principal modes and only five temporal Fourier coefficients (i.e. 45 real numbers) (courtesy of Nastar)

temporal Fourier coefficients, i.e. only 45 real numbers, with such an accuracy that it is possible to recreate a virtual 3D motion again almost impossible to distinguish from the real one (refer elsewhere ${ }^{129-132}$ for a detailed presentation).

Global analysis of nonrigid motion can also be obtained with parameterizable deformable shapes using for instance superquadrics ${ }^{133}{ }^{137}$ or Fourier models ${ }^{138}$. A typical example is shown in Figure 28.

\section{SURGERY SIMULATION}

$\Lambda$ fascinating new field, at the intersection of computer vision, computer graphics and robotics, is the exploitation of $3 \mathrm{D}$ images to planify, simulate and even control 


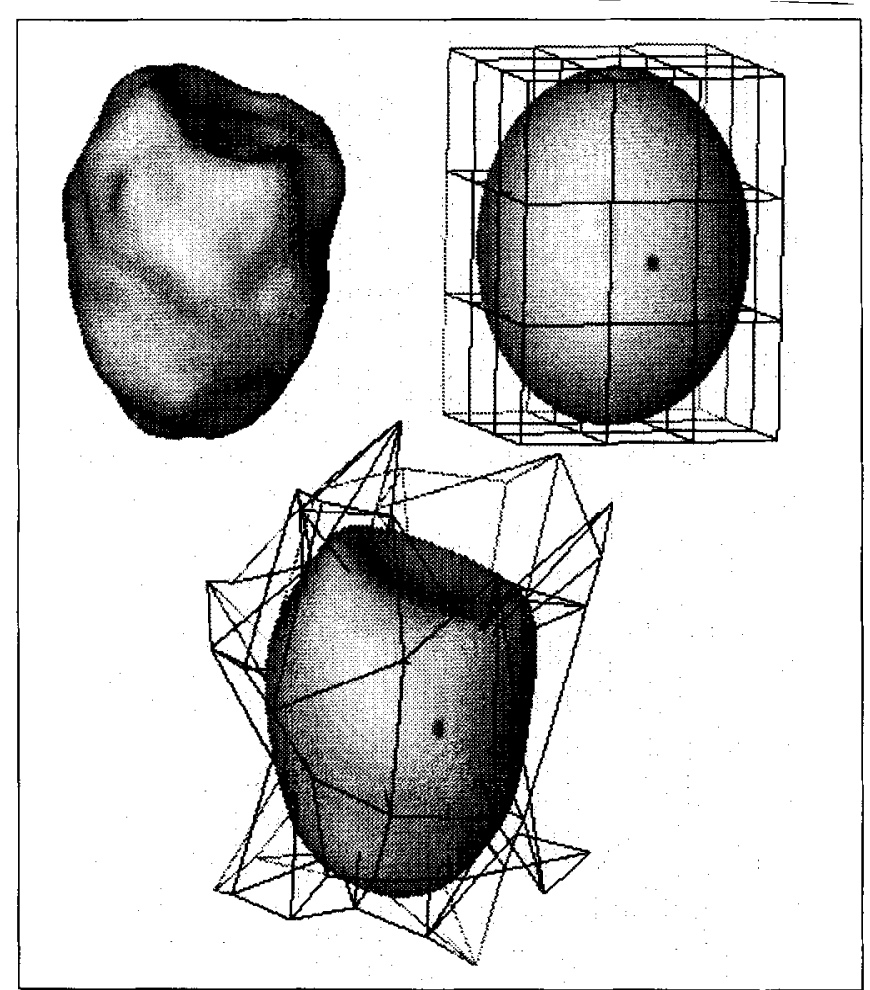

Figure 28 Top right: a superquadric is initialized to fit grossly the left ventricle observed with nuclear medicine imaging (top left). Free from deformations make the local fit much morc accurate at the expense of a few more parameters. These parameters can then be tracked through time to assess quantitative values useful for the diagnosis (courtesy of Bardinet and Cohen)

some complex therapy ${ }^{17-19,139}$. Among them, craniofacial surgery or laparoscopy, for instance, are desperately seeking for pre-operative simulation ${ }^{62,140}$. This can be done with the help of pre-operative 3D image analysis, and the use of advanced interactive 3D graphics involving virtual reality, for instance ${ }^{11,15,16}$.

Currently, in the EPIDAURE project, Delingette and Subsol, with the help of Cotin and Pignon ${ }^{141,142}$, are looking closely at the problem of simulating craniofacial surgery, following the ideas of the pioneering work of Terzopoulos and Waters ${ }^{125}$. This is illustrated by Figures 29 and 30. Also, Bro-Nielsen is currently

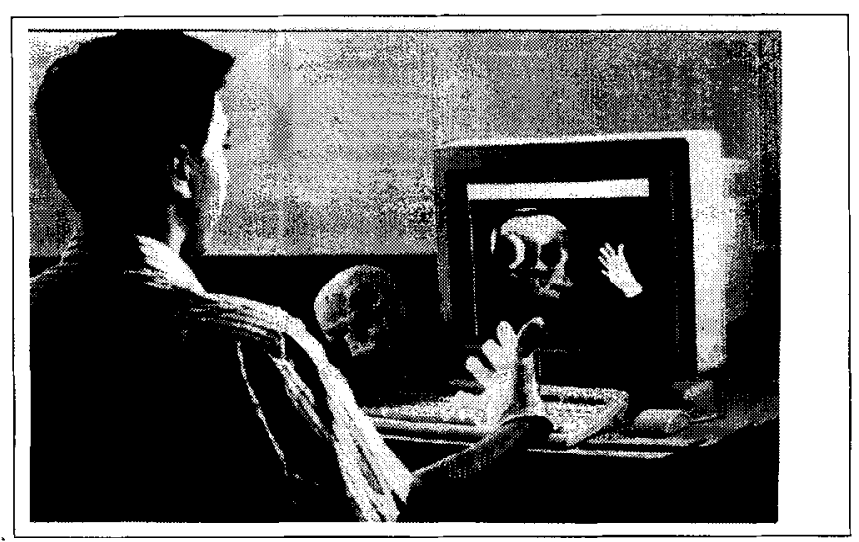

Figure 29 Virtual reality environment for craniofacial surgery simulation (courtesy of Eidelmant and Delingette)

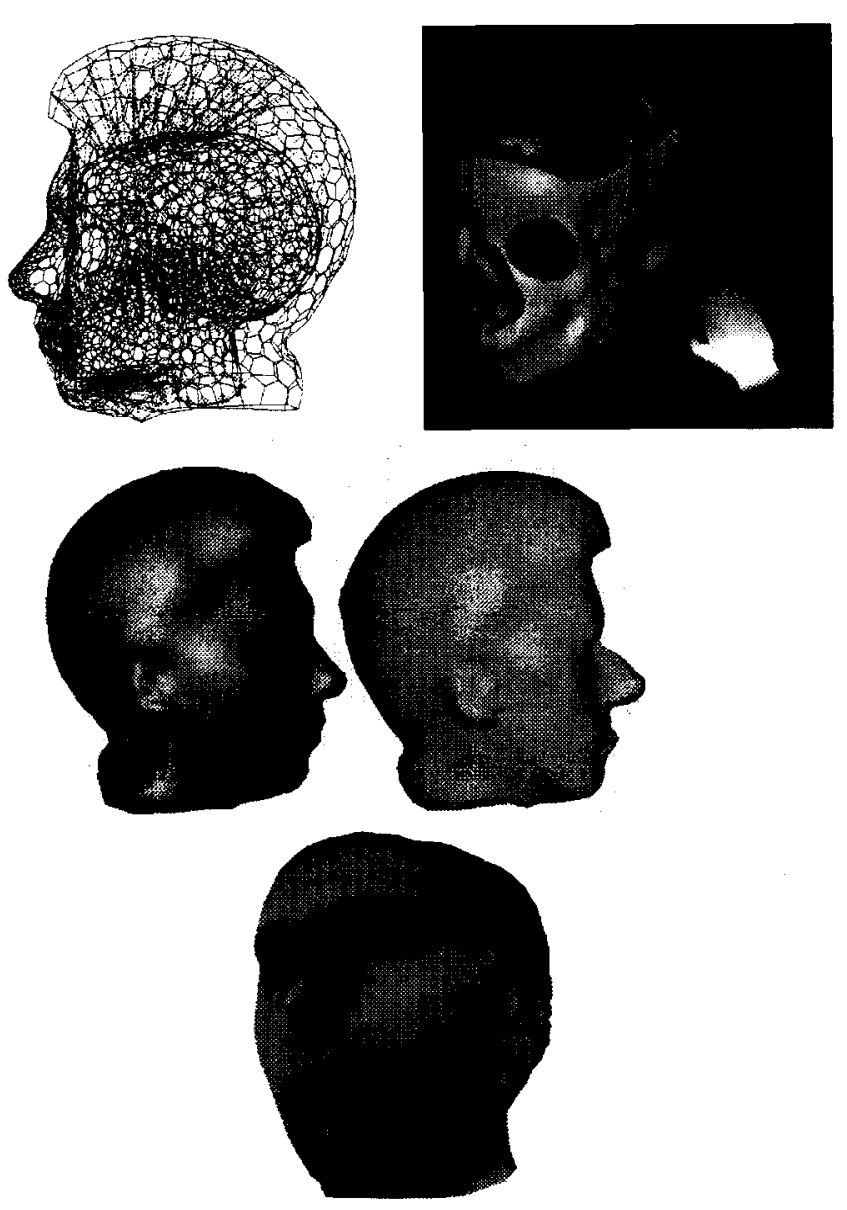

Figure 30 Top left: an elastic model of the head is designed from the $3 D$ image of the head. Top right: the skull is cut and its shape is modified with a virtual 3D hand. Centre and bottom: the elastic model of head of the patient deforms itself accordingly to the modified shape of the skull, and the expected result (a deformed Herve Delingette!) can be observed (possibly with texture) before any real surgery is done (courtesy of Delingette, Subsol, Cotin and Pignon)

trying to model, with adequate tools, the elasticity of human tissues ${ }^{143}$

Another study in the EPIDAURE group is related to augmented reality, acquired by superposing processed preoperative medical images on per-operative medical images (for instance, video images, $\mathrm{x}$-ray images or ultrasound images). Recent results are presented elsewhere ${ }^{144}$, and also in Figures 31 and 32. More advanced work has been presented by the MIT and Harvard teams ${ }^{145}$

The simulation of birth delivery, studied by Geiger and Boissonnat within the PRISME project at INRIA, is described elsewhere ${ }^{146,147}$.

\section{CONCLUSION}

I tried to show in this paper that automating the analysis of 3D medical images is a fascinating field of new research topics related to computer vision, graphics and robotics. I also presented the past and current work of the EPIDAURE research group at INRIA, and tried to determine promising current trends and future challenges for research. 

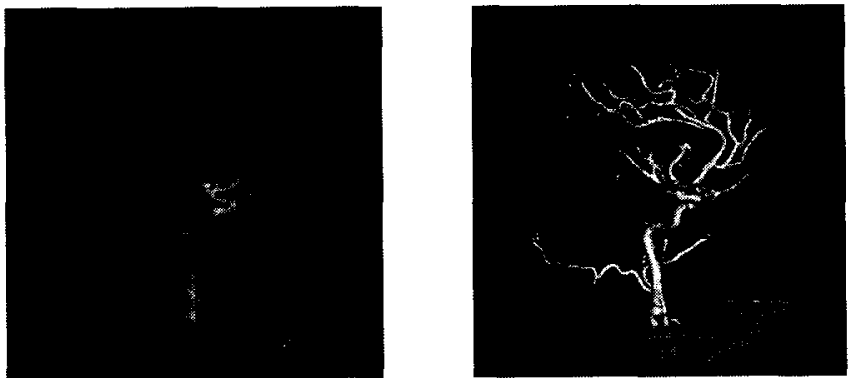

Figure 31 Augmented reality. Finding the geometric transformation between a 3D object and its projective transformation allows us to superimpose a $3 \mathrm{D}$ representation of the brain vessels obtained from MRI (right) with a 2D angiography of the same vessels (left). This is useful to interpret the images during interventional angiography (courtesy of Feldmar. Original images are provided by General Electric Medical Systems Europe, Buc, France)
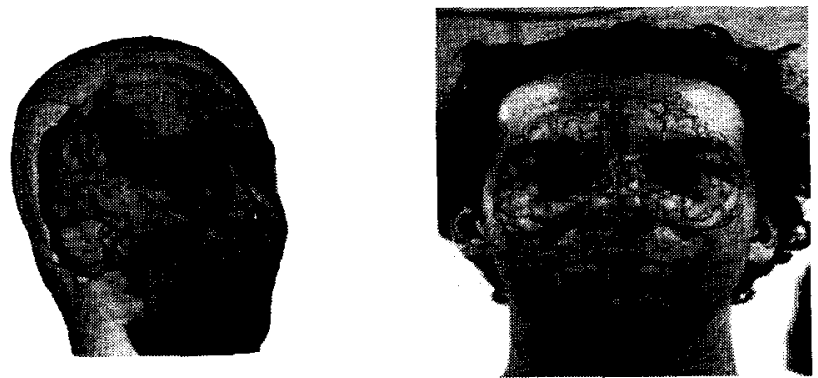

Figure 32 Augmented reality (continued): having computed the geometric transformation between the video images and the preoperative MRI images of the same patient, it is possible to map the video texture on the MRI segmented image (left), and aiso to superimpose his brain surface (MRI) in the video image (right). In this case, it is possible to give the feeling of seeing 'through' the patient, as if he were transparent (courtesy of Feldmar, Betting and Duvernay (robotvis group))

A necessary condition for the success of this research will be the thorough collaboration between research scientists, medical doctors and also members of related hardware and software companies. Another condition will be the establishment of powerful electronic connections between the various departments of the hospital, as well as between hospitals.

Once these conditions are fulfilled, there is no doubt in my mind that medical image processing and medical robotics will become one of the major application fields of computer vision and robotics science, and will bring a revolution in medicine for the coming decade.

\section{ACKNOWLEDGEMENTS}

Of course, acknowledgements go primarily to the researchers of the EPIDAURE group who actively contributed during the past five years to the research work presented in this paper. They are, in alphabetical order, I Cohen, L Cohen, A Guéziec, I Herlin, J LévyVéhel, G Malandain, O Monga, J M Rocchisani and J P Thirion. More recently, important contributions also came from E Bardinet, $S$ Benayoun, $J$ P Berroir, $F$ Betting, S Cotin, J Declerck, H Delingette, J Feldmar,
A Gourdon, P Mignot, X Pennec, C Nastar and G Subsol. This work bencfited from close interactions with R Hummel and $M$ Brady during the sabbatical they spent in our group, as well as the $J$ D Boissonnat, $P$ Boulle, J Brag, P Cinquin, C Cutting, R Kikinis, O Kubler, B Geiger, D Geiger, S Lavallée and $\mathbf{J}$ Travere. Thanks also to our system engineer, $\mathrm{J}$ P Chièze, who made everything work!

Digital Equipement supported a significant part of this research and GE-CGR in Buc, France, supported part of the rigid matching research work. Matra-MS2I and Philips supported part of the research on ultrasound images. Aleph-Med and Focus-Med in Grenoble contribute to the transfer of software towards industry. The European project AIM-Murim supported collaborations with several European imaging and robotics groups. Finally, the ESPRIT European project BRAVIVA supported part of the work on the extraction and use of Euclidean invariants for matching

Many thanks to L Calderan, S Dewez, A Eidelman and B Hidoine, from the Video Department of INRIA, for their help in producing iconic representations of our results, and in particular the movie called 'In Man's Image'.

\section{REFERENCES}

1 Hohne, K, Fuchs, $\mathrm{H}$ and Pizer, $\mathrm{S}$ (eds) $3 D$ Images in Medicine Springer-Verlag, Berlin (1990)

2 Udupa, $\mathrm{J}$ and Herman, $\mathrm{G}$ (eds) $3 \mathrm{D}$ Imaging in Medicine, CRC Press, New York (1991)

3 Robb, R (ed) Visualisation in Biomedical computing, $V B C^{\prime} 92$, Chapel Hill, USA (1992)

4 Barrett, $\mathbf{H}$ and Gmitro, A (eds) Int. Conf. on Information Processing in Medical Images, IPMI'93, Flagstaff, AZ (1993)

5 Wells III, W M, Grimson, E, Kanlade, T and Ayache, N (eds) Applications of Computer Vision in Medical Image Processing AAAI Workshop, Stanford, CA (May 1994)

6 Huang, T (ed) IEEE Workshop on Biomedical Image Analysis, WBIA'94, Seattle, WA (June 1994)

7 Robb, R (ed) Visualisation in Biomedical computing, VBC'94, Mayo Clinic, Rochester, USA (1994)

8 Kanade, T (ed) First Int. Symposium Medical Robotics and Computer Assisted Surgery MRCAS'94, Pittsburgh, USA (September 1994)

9 Ayache, N (ed) First Int. Conf. Comput. Vision, Virtual Reality and Robotics in Medicine, CVRMed'95, Nice, France (April 1995)

10 Hottier, F and Collet-Billon, A '3D echography: Status and perspective', in $\mathrm{K}$ Hohne, $\mathrm{H}$ Fuchs and $\mathrm{S}$ Pizer (eds), $3 D$ Imaging in Medicine, Springer-Verlag, Berlin (1990) pp 21-41

11 Fuchs, $\mathrm{H}$ 'Systems for display of 3D medical image data', in K Hohne, $\mathrm{H}$ Fuchs and $\mathrm{S}$ Pizer (eds), 3D lmaging in Medicine, Springer-Verlag, Berlin (1990) pp 315-331

12 Science et Technologie, Special Issue on Medical Images (February 1991) (in French)

13 Les Echos (5 December 1991) (in French)

14 Le Monde (6 April 1993) p 27 (in French)

15 Kikinis, R, Cline, II, Altobelli, D, Halle, $M$, Lorensen, $\mathrm{W}$ and Jolesz, $F$ 'Interactive visualisation and manipulation of $3 \mathrm{D}$ reconstructions for the planning of surgical procedures', in $\mathrm{R}$ Robb (ed) Visualization in Biomedical Computing, Vol 1808 (1992) pp 559-563

16 Ohbuchi, R, Chen, D and Fuchs, $H$ 'Incremental volume reconstruction and rendering of 3D ultrasound imaging', in $\mathrm{R}$ Robb (ed), Visualization in Biomedical Computing, Vol 1808 (1992) pp 312-323

17 Taylor, R AAn Overview of Computer Assisted Surgery at IBM T. J. Watson Research Center', Proc. 6th Int. Symp. Robotics Res., Pittsburgh, PA (October 1993) 
8 Paul, H, Mittlestadt, B, Bargar, W, Musits, B, Taylor, R, Kazanzides, P, Zuhars, J, Williamson, B and Hanson, W 'A surgical robot for total hip replacement surgery', IEEE Int. Conf. Robotics and Automation, Nice, France (1992) pp 606-611

19 Lavallee, S, Troccaz, J, Gaborit, L, Cinquin, P, Benabid, A L and Hoffmann, D 'Image guided robot: a clinical application in stereotactic neurosurgery', IEEE Int. Conf. Robotics and Automation, Nice, France (1992) pp 618-625

20 Cinquin, $\mathbf{P}$ 'Gestes medico-chirurgicaux assistés par ordinateur', Informatique en Radiologie, Vol 36 Nos 6/7 (1993) pp 386-406 (in French)

21 Stytz, M, Frieder, G and Frieder, $\mathrm{O}$ 'Three-dimensional medical imaging: algorithms and computer systems', $A C M$ Comput. Surv., Vol 23 No 4 (December 1991) pp 421-499

22 Ayache, N, Boissonnat, J D, Cohen, L, Geiger, B, Levy-Vehel, J, Monga, $O$ and Sander, $P$ 'Steps toward the automatic interpretation of 3D images', in K Hohne, H Fuchs and S Pizer (eds), $3 D$ Imaging in Medicine, Springer-Verlag, NATO ASI Series, Vol F60 (1990) pp 107-120

23 Gerig, G, Kuoni, W, Kikinis, $\mathrm{R}$ and Kubler, $\mathrm{O}$ 'Medical imaging and computer vision: an integrated approach for diagnosis and planning', in II Burkhardt, K Hohne and B Neumann (eds) Proc. 11th DAGM Symposium, Vol 219, Sydney, Australia (1989) pp 425-432

24 Schweikard, A, Adler, J and Latombe, J C 'Motion planning in stereotaxic radiosurgery', IEEE Trans. Robotics Automation (1994, to appear)

25 Ayache, N, Cinquin, P,Cohen, I, Cohen, L, Leitner, F and Monga, $O$ 'Segmentation of complex 3D medical objects: a challenge and a requirement for computer assisted surgery planning and performing', in R Taylor and S Lavalee (eds) Computer Integrated Surgery, MIT Press, Cambridge, MA (1994)

26 Monga, O, Deriche, R, Malandain, G and Cocquercz, J P 'Recursive filtering and edge closing: 2 primary tools for $3 \mathrm{D}$ edge detection', Image \& Vision Comput., Vol 9 No 4 (August 1991)

27 Monga, O, Deriche, $\mathrm{R}$ and Rocchisani, J M '3D edge detection using recursive filtering', Comput. Vision, Graph. Image Process., Vol 53 No 1 (January 1991)

28 Deriche, $\mathbf{R}$ 'Using Canny's criteria to derive a tecursively implemented optimal edge detector', Int. I. Comput. Vision Vol 1 No 2 (May 1987)

29 Herman, G T 'Discrete multidimensional jordan surfaces', Comput. Vision, Graph. Image Process.: Graphical Models and Image Processing, Vol 54 No 6 (November 1992) pp 507-515

30 Kong, T Y and Rosenfeld, A 'Digital topology: introduction and survey', Comput. Vision, Graph. Image Process., Vol 48 (1989) pp 357-393

31 Serra, J Image Analysis and Mathematical Morphology, Academic Press, New York (1982)

32 Malandain, G, Bertrand, $\mathrm{G}$ and Ayache, N 'Topological segmentation of discrete surfaces', Int. J. Comput. Vision, Vol 10 No 2 (1993) pp 183-197

33 Bertrand, $G$ and Malandain, $G$ 'A new characterization of threedimensional simple points', Patt. Recogn. Lett., Vol 15 No 2 (February 1994) pp 169-175

34 Kapur, T, Grimson, W E L and Kikinis, R 'Segmentation of brain tissue from $\mathrm{mr}$ images', in N Ayache (ed), First Int. Conf. Comput. Vision, Virtual Reality and Robotics in Medicine CVRMed'95, Nice, France (1995)

35 Wells III, W M, Grimson, W E L, Kikinis, R and Jolesz, F A 'Adaptive segmentation of MRI data', in N Ayache (ed), Firs Int. Comput. Vision. Virtual Reality and Robotics in Medicine. CVRMed'95, Nice, France (1995)

36 Kass, M, Witkin, A and Terzopoulos, D 'Snakes: Active contour models', Int. J. Comput. Vision, Vol 1 (1987) pp 321-331

37 Terzopoulos, D, Witkin, A and Kass, M 'Symmetry seeking models for 3D object reconstruction: Active contour models', Proc. First Int. Conf. Comput. V'ision, London, UK (June 1987)

38 Cohen, L D 'On active contour models and balloons', Comput. Vision, Graph. Image Process.: Image Understanding, Vol 53 No 2 (March 1991) pp 211-218

39 Cohen, I, Cohen, L D and Ayache, N'Using deformable surfaces to segment 3-D images and infer differential structures', Comput. Vision, Graph. Image Process.: Image Understanding, Vol 56 No 2 (1992) pp 242-263

40 Cohen, L D and Cohen I 'Finite element methods for active contour models and balloons for 2-D and 3-D images', IEEE Trans. PAMI, Vol 15 No 11 (November 1993)

41 Ayache, N, Cohen, I and Herlin, I 'Medical image tracking', in A
Blake and A Yuille (eds), Active Vision, MIT Press, Cambridge, MA (1992)

42 Terzopoulos, D and Szeliski, R 'Tracking with Kalman snakes', in A Blake and A Yuille (eds), Active Vision, MIT Press, Cambridge, MA (1992)

43 Curwen, $\mathrm{R}$ and Blake, A 'Dynamic contours: real time active splines', in A Blake and A Yuille (eds), Active Vision, MIT Press, Cambridge, MA (1992)

44 Harris, C 'Tracking with rigid models', in A Blake and A Yuille (eds), Active Vision, MIT Press, Cambridge, MA (1992)

45 Leymarie, $\mathrm{F}$ and Levine, $M$ 'Tracking deformable objects in the plane using an active contour model', IEEE Trans. PAMI, Vol 15 No 6 (1993) pp 635-646

46 Geiger, D, Gupta, A, Costa, L and Vlontzo, J 'Dynamic programming for detecting tracking and matching deformable contours', IEEE Trans. PAMI, Vol 17 No 3 (1995)

47 Leitner, S, Marque, I, Lavallee, S and Cinquin, $P$ 'Dynamic segmentation: finding the edge with spline snakes', in P J L A Le Mehaute and L L Schumaker (eds), Curves and Surfaces, Academic Press, London (1991) pp 279-284

48 Menet, S, Saint-Marc, $\mathrm{P}$ and Medioni, G 'Active contour models Overview, implementation and applications', Syst., Man Cybern (1993) pp 194-199

49 McInerney, $\mathrm{T}$ and Terzopoulos, D 'A finite element model for $3 \mathrm{D}$ shape reconstruction and nonrigid motion tracking', Int. Conf. Comput. Vision, ICCV, Berlin, Germany (1993) pp 518-523

50 Delingette, $\mathrm{H}$, Watanabe, $\mathrm{Y}$ and Suenaga, $\mathrm{Y}$ 'Simplex based animation', in N Magnenat-Thalmann and D Thalmann (eds), Models and Techniques in Computer Animation, Geneva, Switzerland (June 1993) pp 13-28

51 Maitre, $\mathbf{H}$ and Preteux, F Progress in digital image processing with applications to medical imaging, ENST Internal Report. France (1993)

52 Rougon, $\mathrm{N}$ 'On mathematical foundations of local deformations analysis, Mathematical Methods in Medical Imaging II Vol 2035, San Diego, CA (July 1993)

53 Herlin, I L and Ayache, $\mathrm{N}$ 'Feature extraction and analysis methods for sequences of uitrasound images', Image \& Vision Comput., Vol 10 No 10 (December 1992) pp 673-682

54 Herlin, I $\mathbf{L}$ and Ayache, $\mathbf{N}$ 'Feature extraction and analysis methods for sequences of ultrasound images', Proc. Second Euro. Conf. Comput. Vision, Santa Margherita Ligure, Italy (May 1992)

55 Herlin, I L, Nguyen, $\mathrm{C}$ and Graffigne, $\mathrm{Ch}$ ' $\Lambda$ deformable region model using stochastic processes applied to echocardiographic images', Proc. Comput. Vision Patt. Recogn., Champaign, IL (1518 June 1992)

56 Thirion, J-P and Ayache, N Procédé et dispositif d'aide à l'inspection d'un corps, notamment pour la tomographie, Brevet Français, numero 9105138 (April 1991)

57 Thirion, J-P 'Segmentation of tomographic data without image reconstruction', IEEE Trans. Med. Imag., Vol 11 No 1 (March 1992) pp 102-110

58 Levy-Vehel, J Texture analysis using fractal probability functions, INRI^ Research Report, 1707 (1993)

59 Levy-Vehel, J, Mignot, $\mathbf{P}$ and Berroir, J P 'Multifractal, texture and image analysis', CVPR'92, Urbana Champaign, IL (1992)

60 Levy-Vehel, J, Mignot, $\mathrm{P}$ and Berroir, J P Texture and multifractals: New tools for image analysis, INRIA Research Report, $1706(1993)$

61 Kubler, $O$ and Gerig, G 'Segmentation and analysis of multidimensional data sets in medicine', in $\mathrm{K}$ Hohne, $\mathrm{H}$ Fuchs and $\mathrm{S}$ Pizer (eds), $3 D$ Imaging in Medicine, Springer-Verlag, Berlin (1990) pp 63-81

62 Cutting, C 'Applications of computer graphics to the evaluation and treatment of major craniofacial malformations', in $\mathbf{J}$ Udupa and G Herman (eds), 3D Imaging in Medicine, CRC Press (1991) pp 163-189

63 Monga, $O$, Benayoun, $S$ and Faugeras, $O$ 'From partial derivatives of $3 \mathrm{D}$ density images to ridge lines', in M Robb (ed) Visualisation in Biomedical Computing, VBC'92 Chapel Hill, USA (1992) pp 118-129

64 Monga, O, Benayoun, $S$ and Faugeras, $O$ 'From partial derivatives of $3 \mathrm{D}$ volumetric images to ridge lines', IEEE Conf Comput. Vision Patt. Recogn. CVPR'92, Urbana Champaign, IL (1992)

65 Thirion, J-P and Gourdon, A The $3 D$ marching lines algorithm: new results and proofs. INRIA Research Report, 1881 (March 1993)

66 Kalvin, A, Dean, D, I Iublin, J and Braun, $\mathbf{M}$ 'Visualisation in 
anthropology: reconstruction of human fossils from multiple pieces', in A Kaufman and $\mathbf{G}$ Nielsen (eds), Proc. IEEE Visuatization (1992) pp 404410

67 Cutting, C, Bookstein, F, Haddad, B, Dean, D and Kim, D 'A spline based approach for averaging 3D curves and surfaces', Mathematical Methods in Medical Images, San Diego, CA (July 1993)

68 Koenderink, J Solid Shape, MIT Press, Cambridge, MA (1990)

69 do Carmo, M P Differential Geometry of Curves and Surfaces, Prentice-Hall, Englewood Cliffs, NJ (1976)

70 Brady, M, Ponce, J, Yuille, A and Asada, II 'Describing surfaces, in H Hanafusa and H Inoue (eds), Proc. Second Int. Symposium on Robotics Res., Cambridge, MA (1985) pp $5-16$

71 Harr Romeny, B, Florack, L, Salden, A and Viergever, M 'Higher order differential structure of images', in $\mathrm{H} \mathrm{H}$ Barrett and A F Gmitro (eds), Information Processing in Medical Imaging, Flagstaff, AZ (June 1993) pp 77-93

72 Whitaker, $R$ 'Characterizing first and second-order patches using geometry limited diffusion', in H H Barrett and A F Gmitro (eds), Information Processing in Medical Imaging, Flagstaff, AZ (Junc 1993) pp 149-167

73 Gauch, J and Pizer, S 'Multiresolution analysis of ridges and valleys in grey scale images', IEEE Trans. PAMI, Vol 15 No 6 (1993) pp 635-646

74 Morse, B, Pizer, S and Liu, A 'Multiscale medial analysis of medical images', in $\mathrm{H} \mathrm{H}$ Barrett and A F Gmitro (eds), Information Processing in Medical Imaging, Flagstaff, AZ (June 1993) pp 112-131

75 Hosaka, M Modeling of Curves and Surfaces in CAD/CAM, Springer-Verlag, Berlin (1992)

76 Koenderink, J 'Local features of smooth shapes: ridges-and courses', SPIE, Geometric Models in Computer Vision II, San Diego, CA (1993) pp 2-113

77 Monga, O, Ayache, $\mathrm{N}$ and Sander, $\mathrm{P}$ 'Using uncertainty to link edge detection and local surface modelling', Image \& Vision Comput., Vol 10 No 6 (1992) pp 673-682

78 Gueziec, A 'Large deformable splines, crest lines and matching', Int. Conf. Comput. Vision, ICCV, Berlin, Germany (1993)

79 Guéziec, $\mathrm{A}$ and Ayache, $\mathrm{N}$ 'Large deformable splines, crest lines and matching, in Geometric Methods in Computer Vision, San Diego, CA (July 1993)

80 Thirion, J-P, Ayache, N, Monga, O and Gourdon, A Dispositif de traitement d'informations d'images tri-dimensionnelles avec extraction de lignes remarquables, Brevet Français, numero 92 03900 (March 1992)

81 Guéziec, A and Ayache, N 'Smoothing and matching of 3-D space curves', Proc. Second Euro. Conf. Comput. Vision, Santa Margherita Ligure, Italy (May 1992)

82 Lamdan, $\mathrm{Y}$ and Wolfson, $\boldsymbol{H}$ 'Geometric hashing: a general and efficient model-based recognition scheme', Proc. Second Int Conf. Comput. Vision (ICCV) (1988)

83 Ayache, $\mathrm{N}$ and Faugeras, O D 'Hyper: A new approach for the recognition and positioning of two-dimensional objects', $I E E E$ Trans. PAMI, Vol 8 No 1 (January 1986) pp 4454

84 Rigoutsos, I and Hummel, R 'Implementation of geometric hashing on the connection machine', Proc. IEEE Workshop Directions of Automated CAD-Based Vision (1991)

85 Ayache, N Artificial Vision for Mobile Robots: Stereovision and Multisensor Perception, MIT Press, Cambridge, MA (1991)

86 Grimson, E Object Recognition by Computer, MIT Press, Cambridge, MA (1591)

87 Wells III, W M 'Posterior marginal pose estimation', in Proc Image Understanding Workshop, Morgan Kaufmann, San Mateo, CA (January 1992) pp 745-75

88 Stein, F 'Structural hashing: efficient 3D object recognition', Proc. Comput. Vision Patt. Recogn., Maui, HI (June 1991)

89 Faugeras, O $3 D$ Computer Vision, A Geometric Viewpoint, MIT Press, Cambridge, MA (1993)

90 Ayache, N, Gueziec, A, Thirion, J P, Gourdon, A and Knoplioch, J 'Evaluating 3D registration of ct-scan using crest lines', Mathematical Methods in Medical Images, San Diego, CA (July 1993)

91 Pennec, $\mathrm{X}$ and Ayache, $\mathrm{N}$ 'An $o\left(n^{2}\right)$ algorithm for $3 \mathrm{~d}$ substructure matching of proteins', in A Califano, I Rigoutsos and H Wolson (eds), Shape and Pattern Matching in Computational Biology, Plenum, New York (1994)

92 Thirion, J-P 'Extremal points: definition and application to $3 \mathrm{~d}$ image registration', IEEE Proc. Comput. Vision Patt. Recogn., Seattle, WA (June 1994)
93 Thirion, J-P and Benayoun, S Image surface extremal points, new feature points for image registration, INRIA Research Report, 2003 (August 1993)

94 Thirion, J-P 'The extremal mesh and the understanding of $3 \mathrm{~d}$ surfaces', Int. J. Comput. Vision (accepted)

95 Thirion, J-P 'the extremal mesh and the understanding of $3 \mathrm{~d}$ surfaces', IEEE Workshop Biomed. Imag. Analysis (WBIA'94), Seattle, WA (June 1994) pp 3-12

96 Gourdon, A and Ayache, N 'Registration of a curve on a surface using differential properties', 3rd Euro. Conf. Comput. Vision Stockholm, Sweden (May 2-6, 1994) pp 187-192

97 Malandain, $G$ and Rocchisani, J M 'Registration of 3D medical images using a mechanical based method', IEE EMBS Satellite Symposium on $3 D$ Advanced Image Processing in Medicine, Rennes, France (November 2-4 1992)

98 Malandain, G, Fernández-Vidal, S and Rocchisani, J-M 'Improving registration of 3-D medical images using a mechanica based method', 3rd Euro. Conf. Comput. Vision, 136, Stockholm, Sweden (May 2-6 1994) pp 131-801

99 Jiang, H, Robb, R and Holton, $K$ 'A new approach to 3D registration of multimodality medical images by surface match ing', in R Robb (cd), Visualization in Biomedical Computing, Vol 1808 (1992) pp 196-213

100 van den Elsen, $\mathrm{P}$, Maintz, A, Pol, $\mathrm{E}$ and Viergever, $\mathrm{M}$ 'Image fusion using geometrical features', in M Robb (ed), Visualisation in Biomedical Computing, VBC'92, Chapel Hill, USA (1992) pp 172-186

101 Lavallee, S,Szeliski, R and Brunie, L 'Matching 3D smooth surfaces with their $2 \mathrm{~d}$ projections using 3D distance maps', $S P I E$ Geometric Methods in Computer Vision, San Diego, CA (July 25 26 1991)

102 Besl, P J and McKay, N D 'A method for registration of 3D shapes', IEEE Trans. PAMI, Vol 14 (Fcbruary 1992) pp 239 256

103 Zhang, $Z$ 'Iterative point matching for registration of free-form curves and surface', Int. J. Comput. Vision (1995)

104 Bajesy, R, Lieberson, $\mathrm{R}$ and Reivich, M 'A computerized system for the elastic matching of deformed radiographic images to idealized atlas images', J. Computer Assisted Tomography, Vol 7 No 4 (1983) pp 618-625

105 Hohne, K, Pommert, A, Riemer, M, Schiemann, T, Schubert, R and Tiede, $U$ 'Framework for the generation of 3D anatomica atlases', in R Robb (ed) Visualization in Biomedical Computing, Vol 1808 (1992) pp 510.520

106 Subsol, G, Thirion, J-P and Ayache, N 'Steps towards automatic building of anatomical atlases', in R A Robb (ed), Visualization in Biomedical Computing (VBC'94), Rochester, USA (October 1994)

107 Yuille, A L, Hallinan, P W and Cohen, D S 'Feature extraction from faces using deformable templates', Int. J. Comput. Vision, Vol 8 No 2 (1992) pp 99-111

108 Bookstein. F L and Green, W. D K 'Edge information a landmarks in medical images', Visualization in Biomedical Computing, SPIE (1992) pp 242-258

109 Bookstein, F L 'Principal warps: Thin-plate splines and the decomposition of deformations', IEEE Trans. PAMI, Vol 11 No6 (June 1989) pp 567-585

110 Declerck, J, Subsol, G. Thirion, $\mathbf{J} \mathbf{P}$ and Ayache, $\mathbf{N}$ 'Automatic retrieval of anatomical structures in 3d medical images', in $\mathrm{N}$ Ayache (ed), First Int. Conf. Comput. Vision, Virtual Reality and Robotics in Medicine, CVRMed'95, Nice, France (1995)

111 Cootes, T F, Hill, A, Taylor, C J and Haslam, J 'The use of active shape models for locating structures in medical images', in H H Barrett and A F Gmitro (eds), Information Processing in Medical Imaging, Falgstaff, AZ (June 1993) pp 33-47

112 Feldmar, $J$ and Ayache, $N$ 'Rigid and affine registration of smooth surfaces using differential properties', 3rd Euro. Conf Comput. Vision (ECCV'94), Stockholm, Sweden (May 2-6 1994) pp 397-406

113 Feldmar, $\mathrm{J}$ and Ayache, $\mathrm{N}$ 'Locally affine registration of freeform surfaces', IEEE Proc. Comput. Vision Patt. Recogn., Seattle, WA (June (1994)

114 Feldmar, $\mathbf{J}$ and Ayache, $\mathbf{N}$ 'Rigid, affine and locally affine registration of free-form surfaces', Int. J Comput. Vision (1994, accepted)

115 Szeliski, R and Lavallee, S 'Matching 3-d anatomical surfaces with non-rigid deformations using octree-splines', in D Goldgof and R Acharya (eds), Workshop on Biomedical Image Analysis, IEEE (1994) pp 144-153

116 Cohen, I, Ayache, $\mathrm{N}$ and Sulger, $\mathrm{P}$ 'Tracking points on 
deformable curves', Proc. Second Euro. Conf. Comput. Vision, Santa Margherita Ligure, Italy (May 1992)

117 Benayoun, S, Ayache, $\mathrm{N}$ and Cohen, I 'Adaptive meshes and nonrigid motion computation', 12th Int. Conf. Patt. Recogn. (ICPR'94), Jerusalem, Israel (October 9-13, 1994) pp 730 732

118 Benayoun, S, Ayache, $\mathrm{N}$ and Cohen, I An adaptive model for $2 d$ and $3 d$ dense non rigid motion computation, Technical Report 2297, INRIA (May 1994)

119 Benayoun, S Calcul Local du Mouvement, applications à l'imagerie médicale multidimensionnelle, $\mathrm{PhD}$ thesis, Universite Paris Dauphine (December 1993)

120 Duncan, J S, Owen, R L, Staib, L H and Anandan, P 'Measurement ol non-rigid motion using contour shape descriptors', Proc. Comput. Vision Patt. Recogn., Maui, HI (June 1991) pp 318-324

121 Amini, A, Owen, R, Staib, L, Anandan, P and Duncan, J 'Nonrigid motion models for tracking the left ventricular wall', in $A$ Colchester and D Hawkes (eds), Information Processing in Medical Imaging, IPMI'91: Lecture Notes in Computer Science, Springer-Verlag, Berlin (1991)

122 Mishra, S K, Goldgof, D B and Huang, T S Motion analysis and epicardial deformation estimation from angiography data', Proc. Comput. Vision Patt. Recogn., Maui, HI (June 1991) pp 331-336

123 Friboulet, D, Magnin, I, Pommert, A and Amiel, $M$ '3D curvature features of the left ventricle from CT volumic images', SPIE, Mathematical Methods in Medical Imaging, Vol 1768, San Diego, CA (July 1992) pp 182-192

124 Nastar, $\mathrm{C}$ and Ayache, $\mathrm{N}$ 'Fast segmentation, tracking, and analysis of deformable objects', Proc. Fourth Int. Conf. Comput Vision, Berlin, Germany (May 1993)

125 Terzopoulos, D and Waters, $\mathrm{K}$ 'Analysis and synthesis of facia image sequences using physical and anatomical models', IEEE Trans. PAMI, Vol 15 No 6 (1993) pp 569-579

126 Horowitz, $\mathbf{B}$ and Pentland, A 'Recovery of non-rigid motion and structure', Proc. Comput. Vision Patt. Recogn., Maui, HI (June 1991) pp $325-330$

127 Pentland, $\mathrm{A}$ and Sclaroff, $\mathrm{S}$ 'Closed-form solutions for physically based shape modelling and recognition', IEEE Trans. PAMI, Vol 13 No 7 (July 1991) pp 715-729

128 Nastar, C Analytical computation of the free vibration modes. Application to non rigid motion analysis and animation in $3 D$ images, Technical Report 1935, INRIA (June 1993)

129 Nastar, C Modèles physiques déformables et modes vibratoires pour l'analyse du mouvement non-rigide dans les images multidimensionnelles, $\mathrm{PhD}$ thesis, École Nationale des Ponts et Chaussées (July 1994)

130 Nastar, $\mathrm{C}$ and Ayache, $\mathrm{N}$ 'Classification of nonrigid motion in $3 \mathrm{~d}$ images using physics-based vibration analysis', IEEE Workshop on Biomedical Image Analysis (WBIA'91), Seattle, WA (June 1994)

131 Nastar, $\mathrm{C}$ and Ayache, $\mathrm{N}$ 'Deformable 3D objects: using modes and FFT for a quantitative analysis of non rigid motion', IEEE Workshop on Object Representation for Computer Vision, Now York, USA (December 1994)

132 Benayoun, S, Nastar, $C$ and Ayache, $N$ 'Dense non-rigid motion estimation in sequences of $3 \mathrm{~d}$ images using differential constraints', in N Ayache (ed), First Int. Conf. Comput. Vision,
Virtual Reality and Robotics in Medicine, CVRMed'95. Nice, France (1995)

133 Bardinet, E, Cohen, L D and Ayache, N 'Fitting of iso-surfaces using superquadrics and free-form deformations', IEEE Work shop on Biomedical Images Analysis (WBIA'94), Seattle, WA (June 1994)

134 Bardinet, E, Cohen, L and Ayache, N 'Superquadrics and freeform deformations: a global model to fit and track $3 \mathrm{~d}$ medical data', in N Ayache (ed) First Int. Conf. Comput. Vision, Virtual Reality and Robotics in Medicine, CVRMed'95, Nice, France (1995)

135 Terzopoulos, D and Metaxas, D 'Dynamic 3-D models with local and global deformations. Deformable superquadrics', IEEE Trans. PAMI, Vol 13 No 7 (1991) pp 703-714

136 Metaxas, D and Terzopoulos, D 'shape and non-rigid motion estimation through physics-based synthesis', IEEE Trans. PAMI, Vol 15 No 6 (1993) pp 580-591

137 Vemuri, B, Radisavljevic, A and Leonard, C 'Multiresolution stochastic 3D shape models for image segmentation', in $\mathbf{H} \mathbf{H}$ Barrett and A F Gmitro (eds), Information Processing in Medical Imaging, Flagstaff, AZ (June 1993) pp 62-76

138 Staib, L and Duncan, J 'Deformable fourier models for surface finding in 3D images', in $\mathbf{R}$ Robb (ed), Visualization in Biomedical Computing, Vol 1808, SPIE (1992) pp 90-104

139 Baker, $\mathbf{H}$, Bruckner, J and Langdon, J "Estimating ankle rotational constraints from anatomic structure', in $\mathbf{R}$ Robb (ed) Visualization in Biomedical Computing, Vol 1808 (1992) pp 422432

140 Marchac, D and Renier, D 'New aspects of crano-facial surgery', World J. Surgery, Vol 14 (July 1990) pp 725-732

141 Delingette, H, Watanabe, $\mathrm{Y}$ and Suenaga, $\mathrm{Y}$ 'Simplex based animation', in N Magnenat-Thalmann and D Thalmann (eds) Models and Techniques in Compute Animation, Geneva, Switzerland (June 1993) pp 13-28

142 Delingette, H, Subsol, G, Cotin, S and Pignon, J 'A craniofacial surgery simulation testbed', in $\mathbf{K}$ A Robb (ed), Visualization in Biomedical Computing (VBC'94), Rochester, Minnesota, USA (October 1994)

143 Bro-Nielsen, M 'Modelling elasticity in solids using active cubesapplication to simulated operations', in N Ayache (ed), First Int Conf. Comput. Vision, Virtual Reality and Rohotics in Medicine, CVRMed'95, Nice, France (1995)

144 Betting, F, Feldmar, J, Ayache, N and Devernay, F 'A new framcwork to fusc stcreo images with volumetric medical images', in N Ayache (ed), First Int. Conf. Comput. Vision, Virtual Reality and Robotics in Medicine, CVRMed'95, Nice, France (1995)

145 Grimson, W E L, Ettinger, G J, White, S J, Gleason, P L Lozano-Perez, T, Wells III, W M and Kikinis, R 'Evaluating and validating an automated registration system for enhanced reality visualization in surgery', in $\mathrm{N}$ Ayache (ed), First Int. Conf. Comput. Vision, Virtual Reality and Rohotics in Medicine CVRMed'95, Nice, France (1995)

146 Geiger, B '3D simulation of delivery for cephalopelvic distortion', First Int. Works. Mechatronics and Surgery, Costa del Sol, Spain (October 1992)

147 Boissonnat, J-D and Geiger, B $3 D$ reconstruction of complex shapes based on the Delannay triangulation, INRIA Research Report, 1697 (1992) 